Esta revista forma parte del acervo de la Biblioteca Jurídica Virtual del Instituto de Investigaciones Jurídicas de la UNAM

\title{
La superación de la doctrina clásica en torno a la subjetividad internacional en detrimento de las multinacionales
}

\section{Overcoming the Classical Doctrine of International Subjectivity at the Expense of Multinationals}

\author{
Le dépassement de la doctrine classique \\ autour de la subjectivité internationale \\ au détriment des multinationales
}

Jacqueline Hellman*

\begin{abstract}
SUMARIO: I. Introducción. II. La soberanía estatal como condición previa y necesaria en la configuración del orden jurídico internacional. III. Los otros consagrados sujetos no estatales de la regulación internacional. IV. El complejo estatus de las personas físicas y jurídicas en el orden legal internacional actual. V. ¿Es la actuación de la Organización de las Naciones Unidas una táctica para promover la subjetividad internacional de las personas jurídicas? VI. Conclusiones. VII. Bibliografía.
\end{abstract}

* Acreditada como profesora contratada desde mayo 2017; es doctora en derecho por la Universidad Autónoma de Madrid bajo la dirección del profesor Antonio Remiro Brotóns. En la actualidad, imparte las siguientes asignaturas en varios centros universitarios: Derecho internacional público, Derecho de la Unión Europea y Derechos humanos.

Artículo recibido el 5 de junio de 2017 Aprobado para publicación el 25 de septiembre de 2017 
Resumen: A la luz del debate auspiciado por la Organización de las Naciones Unidas en los últimos años, parece apropiado plantearse el estatus actual que ostentan las personas jurídicas en el ámbito de la regulación internacional, el cual se ha visto especialmente agravado tras la presentación del informe elaborado por el ex representante especial del secretario general, John Ruggie. La trascendencia de este tipo de estrategias radica en la posibilidad de que la comunidad internacional opte por la cristalización de una concepción amplia de la civitas maxima, rompiendo frontalmente con la concepción clásica relativa a la subjetividad internacional. De cualquier forma, falta esperar y comprobar si finalmente las acertadas — aunque, en ocasiones, poco tajantes - medidas adoptadas hasta la fecha culminan de forma exitosa, impulsando una auténtica y eficaz protección de las normas relativas a los derechos humanos en un sector tan controvertido como es, sin duda, el empresarial.

Palabras clave: subjetividad internacional, personas jurídicas, civitas maxima, principios rectores de Ruggie, Organización de las Naciones Unidas, derechos humanos.

ABSTRACT: In the light of the debate under the auspices of the United Nations Organization in recent years, it seems appropriate to consider the current status of legal persons in the field of international regulation, which has been particularly aggravated by the presentation of the report drawn up by the former Special Representative of the Secretary-General, John Ruggie. The importance of this type of strategy lies in the possibility that the international community opts for the crystallization of a broad conception of the civitas maxima, breaking frontally with the classical conception that refers to international subjectivity. Be that as it may, we must wait and see whether the successful - though sometimes blunt - measures taken to date successfully culminate in a truly effective protection of human rights standards in such a controversial sector as, without doubt, is the business one.

Key words: international subjectivity, civitas maxima, Ruggie's guiding principles, United Nations Organization, human rights.

RÉSUMÉ: À la lumière du débat sous les auspices des Nations Unies au cours des dernières années, il semble approprié d'examiner le statut actuel des personnes morales dans le domaine de la réglementation internationale, ce qui a été particulièrement aggravé suite à la présentation du rapport élaboré par l'ancien Représentant spécial du Secrétaire général, John Ruggie. L'importance de ce type de stratégie réside dans la possibilité que la communauté internationale opte pour la cristallisation d'une conception large de la civitas maxima en rupture avec la conception classique relative à la subjectivité internationale. Quoi qu'il en soit, nous devons attendre et voir si les mesures qui ont eu du succès — mais parfois trop douces — prises à ce jour aboutissent à une protection véritablement efficace des normes relatives aux droits de l'homme dans un secteur aussi controversé que celui-ci.

Mots-clés: subjectivité internationale, civitas maxima, principes directeurs de Ruggie, Organisation des Nations Unies, droits de l'homme. 
Esta revista forma parte del acervo de la Biblioteca Jurídica Virtual del Instituto de Investigaciones Jurídicas de la UNAM

\section{INTRODUCCIÓN}

La sociedad internacional actual presenta una naturaleza marcadamente estatal; sin embargo, no debe desdeñarse el rol que otros actores ejercen en las actuales y complejas relaciones internacionales, así como el incuestionable proceso de humanización al que se encuentra sometido el derecho internacional contemporáneo. Ambos factores han transformado la "fisonomía" de este último, lo cual se ha materializado, inter alia, en el reconocimiento de una personalidad jurídica internacional a favor de ciertos actores no estatales. Así pues, a la luz del contexto actual, no debe resultarnos ajeno el debate que se plantea en torno a si las personas físicas y jurídicas pueden ser consideradas sujetos desde el punto de vista de la regulación supranacional, aunque tradicionalmente no sean consideradas como tales.

En este orden de ideas, debemos subrayar que muchos autores se han decantado — no sin afrontar numerosos obstáculos - por atribuir personalidad jurídica internacional al individuo. Aun cuando este extremo no constituye un capítulo cerrado en la medida en que quedan todavía numerosas cuestiones por dilucidar, resulta todavía más acuciante abordar la incipiente discusión surgida en torno a las personas jurídicas, puesto que es en este ámbito en el que surgen controvertidas interrogantes y dificultades de hondo calado.

Consecuentemente, parece apropiado determinar - como haremos a continuación - el estatus actual que ostentan aquéllas más allá del plano doméstico, máxime si advertimos que la Organización de Naciones Unidas se inclina, hasta la fecha, por reconocer su subjetividad internacional; a nuestro modo de ver, ello redundaría en una concepción amplia de la civitas maxima y, además, en un ruptura frontal y desafiante para con la concepción clásica de la subjetividad internacional. Veremos, pues, en los siguientes apartados, si medidas como las propuestas por el ex representante especial del secretario general, John Ruggie, impulsan realmente una protección eficaz de las normas relativas a los derechos humanos en un sector tan controvertido como es, sin duda, el empresarial. Asimismo, determinaremos si éstas, de algún modo, provocan la superación de la doctrina clásica en torno al encorsetado y limitado concepto relativo a la subjetividad internacional. 
Esta revista forma parte del acervo de la Biblioteca Jurídica Virtual del Instituto de Investigaciones Jurídicas de la UNAM

\section{LA SOBERANÍA ESTATAL COMO CONDICIÓN PREVIA Y NECESARIA} EN LA CONFIGURACIÓN DEL ORDEN JURÍDICO INTERNACIONAL

Tradicionalmente, el concepto de soberanía ha hecho referencia a la categoría clásica del Estado en virtud de la cual se sostenía su poder absoluto y perpetuo, estableciendo los principios reguladores de la sociedad sobre la que quedaba proyectada. Con el tiempo, dicho concepto se ha ido adaptando a las democracias actuales como una expresión del momento político en el que los ciudadanos, sin ninguna autoridad previa ni superior, permiten a los poderes públicos ejercer su función. ${ }^{1}$ Además, el referido concepto de soberanía ha presentado diversas acepciones, pues no sólo se ha aplicado en el ámbito interno estatal, sino que también se ha caracterizado por acoger una dimensión externa estrechamente vinculada a la capacidad de los Estados de declarar la guerra o firmar la paz.

Consecuentemente, no hay duda de que el referido concepto presenta una vertiente externa irremediablemente ligada a la existencia de la propia regulación internacional, tal y como se deduce de la siguiente afirmación: "la virtualidad del DI [derecho internacional] está confirmada por la experiencia, la práctica de los Estados y la jurisprudencia”. ${ }^{2}$ Actualmente, esta perspectiva externa de la soberanía hace referencia, entre otras cuestiones, a la predisposición y a la conducta general estatal de no intervenir en los asuntos domésticos de otros Estados. ${ }^{3}$ Es más, en línea con lo anterior cabe determinar que "en materia de fuentes de producción del derecho internacional en relación con el principio de igualdad soberana concierne

1 Véase Vázquez, C. M., "Aproximación al concepto de soberanía en el marco de las relaciones internacionales”, REJES, vol. I, 2003, p. 3.

2 Cfr. Remiro Brotóns, A. et al., "Soberanía e igualdad soberana de los Estados", Derecho Internacional, Madrid, Mc Graw Hill, 2007, p. 47. En este orden de ideas, se afirma además que la sociedad internacional "es original y básicamente la sociedad de los Estados soberano a independientes en situación de yuxtaposición”. Idem.

3 Desde este punto de vista, la soberanía es una noción jurídico-política propia de las relaciones internacionales; en definitiva, hace referencia a la idea de independencia del Estado como único sujeto con poder de decisión autónomo en el ámbito de sus competencias. Junto a ello, no hay que olvidar que el conjunto de Estados protagoniza relaciones recíprocas de realidad formal en un contexto descentralizado en el que no existen entidades supranacionales. Ibidem, p. 5. 
Esta revista forma parte del acervo de la Biblioteca Jurídica Virtual del Instituto de Investigaciones Jurídicas de la UNAM

al valor del consentimiento de los Estados en la creación de obligaciones internacionales. El consentimiento de los Estados ha sido siempre considerado como la piedra angular del derecho internacional". ${ }^{4}$ De esta manera, resulta de gran interés puntualizar en el apartado siguiente el modo en el que el comentado concepto evoluciona hasta verse estrechamente ligado a la propia configuración del derecho internacional.

\section{Evolución del concepto de soberanía y su relación con el derecho internacional}

La soberanía es el concepto clave de la teoría clásica del Estado, se caracteriza por un poder absoluto e ilimitado que surge en el siglo XVI bajo el amparo del Estado moderno, centralizado y burocrático, como consecuencia de las luchas sostenidas por la monarquía francesa contra el imperio, la Iglesia y los señores feudales a finales de la Alta Edad Media. La presencia del Estado moderno dio nacimiento a una concepción nueva de ese poder. $\mathrm{Al}$ respecto, Bodin afirmó que: "la soberanía es el poder absoluto y perpetuo que los latinos llamaron majestad”. ${ }^{5}$ Así, la soberanía, según dicho autor, se configuraba como un poder absoluto y perpetuo que el príncipe ostentaba (entendiendo por absoluto su capacidad de elaborar y derogar leyes de forma ilimitada en el tiempo). Por lo tanto, a finales del siglo XVI, la soberanía como poder supremo sobre cierto territorio o espacio físico constituía una realidad política indiscutible. Posteriormente, se dio un paso más y se añadió que la soberanía residía en el pueblo, erigiéndose como comienzo y final de toda organización política. ${ }^{6}$

4 Cfr. Esposito, C. "Soberanía e igualdad en el Derecho Internacional", Anuario de la Facultad de Derecho de la Universidad Autónoma de Madrid, vol. 13, 2009, p. 303.

5 Cfr. Bodin, J., "Libro primero; Capítulos VII-X”, Los Seis Libros de la República, trad. de Pedro Bravo, Madrid, Aguilar, 1973, pp. 44 y ss.: "La souveraineté est la puissance absolute et perpetuelle que les latins apellent maiestatem”. Bodin es el primer autor que da forma al concepto de soberanía.

6 A este respecto, Rousseau señaló que: "El acto que instituye el Gobierno no es un contrato, sino una ley; los depositarios del poder ejecutivo no son los dueños del pueblo, sino sus servidores; puede nombrarlos o destituirlos cuando le plazca; no es cuestión para ellos de contratar, sino de obedecer, y encargándose de las funciones que el Estado les impone no hace sino cumplir con su deber de ciudadano, sin tener en modo alguno el derecho de discutir las condiciones". Cfr. Rousseau, J.J., "Libro III; Capítulo XVIII", El contrato social, trad. de Luis Blanco Vila, Madrid, Torre de Goyanes, 2001, p. 121. En otras palabras, estábamos ante una 
Esta revista forma parte del acervo de la Biblioteca Jurídica Virtual del Instituto de Investigaciones Jurídicas de la UNAM

En relación con las observaciones anteriores, conviene apuntar que la idea fundamental por la que se produce el desarrollo imparable del concepto de soberanía responde a las pretensiones y a las exigencias de robustecimiento del Estado - tanto por razones históricas como políticas - que vinieron a trasladar el referido concepto al círculo o ámbito estatal. ${ }^{7}$ Consecuentemente, al no estar interesados la mayor parte de los teóricos políticos en las relaciones interestatales, resulta lógica la dificultad de aplicar en el orden jurídico internacional un concepto propio de la teoría política del Estado.

No obstante, la relación del comentado concepto con el orden internacional es indiscutible y necesaria, por lo que quizá habría - con el propósito de evitar constantes confusiones - que reemplazar el término "soberanía" cuando sea utilizado bajo el ámbito de dicho orden jurídico o, quizá, dotarlo de un significado más preciso, y adaptarlo así a las exigencias de la doctrina internacional. ${ }^{8}$ Sea como fuere, la innegable relación existente entre el concepto de soberanía y el orden internacional no surgió en la época en la que se empezaron a vislumbrar los inicios del sistema del derecho internacional; es decir, hace aproximadamente trescientos cincuenta años, ${ }^{9}$ momento en el cual se estableció la igualdad entre los Estados, así como una delimitación clara de sus territorios y de sus respectivas competencias, dejando el ámbito territorial como el lugar de actuación estatal $;{ }^{10}$ dicha conexión fue posterior.

soberanía popular bajo la que se consideraba que todos los poderes y facultades estaban en manos del pueblo y de él derivaban; la soberanía en aquel entonces procedía de un contrato o pacto surgido como consecuencia de la enajenación de parte de la voluntad de cada individuo para formar la voluntad general soberana.

7 Prueba de ello es la teoría hegeliana relativa a la supremacía absoluta del Estado, en virtud de la cual ese poder difuso, la soberanía, se adentra en el referido ámbito estatal. Véase Hegel, G. F., "El Estado", Filosofía del derecho, trad. de Angélica Mendoza de Montero, Buenos Aires, Claridad, 1987, pp. 208 y ss. Para Hegel la voluntad del Estado es la absoluta soberanía y la fuente de toda validez legal.

8 Véase Sepúlveda, C., "Soberanía y derecho internacional”, Derecho internacional público, 2a. ed., México, Porrúa, 1964, p. 81.

9 Así quedó reflejado en la Paz de Westfalia, la cual sentó las bases más esenciales en las relaciones internacionales de la Edad Moderna, promoviendo un equilibrio europeo que impidiera a unos Estados imponerse sobre otros. Sus efectos se mantuvieron hasta las guerras y revoluciones nacionalistas del romántico siglo XIX.

10 Véase Brown Weiss, E., "Invoking State Responsibility in the Twenty-first Century”, AJIL, vol. 96, núm. 4, 2002, p. 798. 
Esta revista forma parte del acervo de la Biblioteca Jurídica Virtual del Instituto de Investigaciones Jurídicas de la UNAM

Así pues, para apreciar el vínculo entre uno y otro resulta imprescindible dejar a un lado la visión tradicional del concepto de soberanía y decantarse por una noción amplia de la idea de la comunidad internacional, ${ }^{11}$ admitiendo la notable influencia que ésta ejerce en el ámbito estatal. ${ }^{12}$ De todo ello, se deduce que la voluntad del Estado, como ente libre y soberano, auspicia y formula la normativa internacional bajo la conjunción de distintas culturas e intereses existentes, siendo la soberanía la vía por la que los principios que rigen la comunidad quedan recogidos y positivados como reglas máximas.

En definitiva, la soberanía queda configurada como un mecanismo válido para determinar los preceptos supremos obligatorios de la comunidad. En este orden de ideas, hay que puntualizar que la soberanía no consiste en un grado superior de poder ni en un monopolio de mando estatal; su poder tan sólo es un medio para el cumplimiento de la función soberana. Dar un paso más en torno a todas estas cuestiones supondría dotar al citado concepto de un sentido funcional, ${ }^{13}$ ya que la referida funcionalidad implicaría que el mismo dejaría de formar parte inherente del Estado para convertirse en una realidad dinámica que implicaría la consideración del derecho internacional como un orden jurídico de entes soberanos a

11 Véase Hart, H. L., "Legal Positivism", International Rules, NuevaYork, Oxford University Press, 1996, p. 60. Este autor desarrolla el concepto capital de la comunidad internacional de la siguiente manera: "The International community is a decentralized community, decentralized in a specific manner, whereas the state is a centralized community. It is essentially in the degree of centralization that an international community constituted by international law differs from a national community constituted by national law, a union of states from a state". Cfr. Hart, H. L., op. cit., pp. 60 y 61.

12 En este sentido, es de sumo interés traer a colación las palabras de Heller: "la eficiencia del derecho internacional está fundada en la voluntad común de los Estados y en la validez de los principios ético-jurídicos. Los Estados actualizan o positivan los principios jurídicos, los cuales, en su conjunto, forman los preceptos de derecho internacional. Y son los sujetos de este orden jurídico, libres, soberanos y jurídicamente iguales, los que formulan el derecho internacional. Como todo derecho, el internacional es producto de una comunidad de culturas e intereses que ningún político puede crear de manera artificial. Soberanía, entonces, es la capacidad de positivar los preceptos supremos obligatorios para la comunidad. Su esencia es, en suma, la positivación — en el interior del Estado - de principios o preceptos jurídicos supremos determinantes de la comunidad". Cfr. Heller, H., "El Estado", Teoría del Estado, trad. de Luis Tobio. México, Fondo de Cultura Económica, 1983, pp. 242 y 243.

13 Véase Espósito, C., "Derecho y política en la sociedad internacional: Ensayo sobre la autonomía relativa del derecho internacional”, RJUIPR, vol. 34, núm. 1, 1999, p. 32. 
Esta revista forma parte del acervo de la Biblioteca Jurídica Virtual del Instituto de Investigaciones Jurídicas de la UNAM http://www.juridicas.unam.mx/ https://biblio.juridicas.unam.mx/bjv DOI: http://dx.doi.org/10.22201/iij.24487872e.2018.18.12106

https://revistas.juridicas.unam.mx/

los que obliga. Así fue precisamente como lo creyó Sepúlveda. ${ }^{14} \mathrm{~A}$ estos efectos, el mencionado autor manifiesta que: a) el ordenamiento jurídico internacional se constituye como un conjunto de normas a las que quedan obligados los entes soberanos, y que $b$ ) la soberanía del Estado es la "capacidad de crear y de actualizar el derecho, tanto [en] el [plano] interno como el internacional" junto con la obligación de actuar conforme al mismo. ${ }^{15}$ De dichas premisas cabe deducir la supremacía del derecho internacional. ${ }^{16}$

A raíz de la afirmación relativa a que la soberanía del Estado presenta un marcado carácter funcional, cabe deducir una premisa esencial:

la soberanía es entendida como el conjunto de competencias que son atribuidas a un Estado por el derecho internacional, ejercitables en un plano de independencia e igualdad. Su manifestación más relevante en el ámbito de las relaciones internacionales es su capacidad para obligarse con otros y su responsabilidad internacional en caso de incumplimiento. ${ }^{17}$

14 Véase Sepúlveda, C., op. cit., p. 82.

15 Idem.

16 El primer caso en el que se reconoció la supremacía del derecho internacional fue, posiblemente, en el asunto de las Reclamaciones de Alabama (Alabama Claims) de 1872 que enfrentaba a Estados Unidos contra Gran Bretaña. El país norteamericano que reclamaba la reparación de los daños causados por unos buques de guerra construidos en Liverpool — bajo el auspicio británico - y entregados a los secesionistas del sur de Estados Unidos supuso la celebración del Tratado de Washington de 1871 en virtud del cual se creó un tribunal arbitral. El mencionado tratado establecía que Gran Bretaña no podía exonerarse de cumplir con sus obligaciones internacionales de neutralidad bajo el pretexto de cumplir con sus respectivas normas constitucionales.

17 Cfr. Remiro Brotóns, A., et. al, op. cit., p. 127. Se deduce, por tanto, que la existencia de múltiples entes soberanos genera, en el marco internacional, la necesidad de crear y desarrollar normas que regulen una adecuada distribución de competencias con el propósito de evitar situaciones conflictivas, siendo precisamente en este ámbito en el que derecho internacional juega un papel fundamental. Un asunto de relevancia a estos efectos fue aquel que tuvo lugar en 1923 ante la Corte Permanente de Justicia Internacional, posteriormente sucedida por la Corte Internacional de Justicia, conocido como el asunto SS Wimbledon, a través del cual se puso de relieve la necesidad de restringir los derechos soberanos de los Estados, junto con la idea imperiosa de proceder a la adopción de nuevos compromisos internacionales, entendiendo que los mismos no constituían una restricción de la propia soberanía, sino que eran apreciados como un atributo de la misma. A raíz de este asunto cabe concluir que no existe conflicto alguno entre la soberanía de un Estado y la normativa internacional, ya que es aquélla la que atribuye la capacidad a un país para quedar obligado por la regulación internacional — aunque 
Esta revista forma parte del acervo de la Biblioteca Jurídica Virtual del Instituto de Investigaciones Jurídicas de la UNAM

Al margen de dotar a la soberanía de un sentido funcional, conviene tener presente que su significado varía en función de que se esté hablando de la coexistencia o no coexistencia de un Estado con otras entidades semejantes, ya que en el supuesto en el que la primera tenga lugar, la formulación jurídica de la soberanía se llevaría a cabo en términos de igualdad entre los diversos Estados. Lógicamente, cuando un Estado es analizado bajo la presencia de otras entidades de naturaleza semejante, el citado concepto mostrará importantes matices en la medida en que ningún ente territorial reconocerá la superioridad de otro, a pesar de que es posible que se admitan las pretensiones planteadas por los Estados sobre una regla de conducta basada en la idea de reciprocidad. Es en este punto en el que se aprecian los principios fundamentales que explican la convivencia entre los entes soberanos junto con el importante papel que juega la normativa internacional. ${ }^{18}$ Esta relación muestra que no se produce colisión alguna entre el Estado y el derecho internacional. De hecho, su interrelación es inevitable, ya que en el momento en el que un Estado se relaciona con otro - lo que hoy en día es absolutamente incuestionable - se hace necesaria la presencia de determinados principios, como el de reciprocidad, para regir y regular este tipo de situaciones.

Siguiendo el hilo de la argumentación anterior, Carpizo afirma que no existe "antagonismo entre el Estado soberano y el derecho internacional y la base de este último es la existencia de Estados soberanos que al no vivir aislados entran en relación sobre la base de ciertos principios como

es factible que compromisos nuevos de estas características mermen o limiten de alguna forma la competencia estatal-.

18 Los referidos principios quedan plasmados a continuación: "I. Aún sin su consentimiento, los sujetos del derecho internacional están obligados por las normas del derecho de gentes consuetudinario que le resulten aplicables y por los principios generales de derecho reconocidos por las naciones civilizadas; II. Pueden imponerse a un sujeto del orden legal internacional, obligaciones internacionales adicionales sólo con su consentimiento; III. El ejercicio de la jurisdicción territorial es exclusivo para cada Estado, a menos de que estuviere limitado o exceptuado por normas de derecho internacional; IV. En ciertos y especiales casos, los sujetos de derecho internacional pueden pretender jurisdicción sobre cosas o persona afuera de su jurisdicción territorial, y V. A menos que existan reglas que lo permitan, la intervención de un sujeto de derecho internacional en la esfera de la exclusiva jurisdicción doméstica de otro sujeto constituye una ruptura del orden jurídico internacional”. Éstos se han tomado de: Scwarzenberger, G., "Introduction of International Law", A Manual of International Law, 5a. ed., Londres, Stevens and Sons, 1967, p. 65. 
Esta revista forma parte del acervo de la Biblioteca Jurídica Virtual del Instituto de Investigaciones Jurídicas de la UNAM

el de reciprocidad". ${ }^{19}$ Continuando con este discurso, resulta obvio que la presencia no sólo de otros Estados sino también de organizaciones internacionales puede llegar a resultar "molesta" en ocasiones, puesto que influye en gran medida sobre la forma en la que un Estado se relaciona. En otras palabras, las competencias y los poderes que, por ejemplo, una organización internacional puede ostentar determinan, en algunos casos, el funcionamiento y la actuación estatal. Consecuentemente, éstas deben tener excesivo cuidado con las acciones que ejerciten, ya que pueden ir en contra del régimen interior de un Estado, que puede ser, además, uno de sus miembros. ${ }^{20}$

Sea como fuere, no hay duda de que los Estados desempeñan un papel crucial en la esfera de la regulación supranacional, lo cual deriva de la propia idea de soberanía en la medida en que ésta se erige como el atributo esencial por medio del cual se confiere a éstos la capacidad de asumir obligaciones supranacionales y la consecuencia, por tanto, de apreciar su responsabilidad en caso del incumplimiento de aquéllas. ${ }^{21} \mathrm{~A}$ raíz de las consideraciones anteriores, no hay posibilidad de refutar la idea de que los Estados son sujetos plenos, primarios y necesarios en el ámbito de la regulación internacional, disponiendo per se de subjetividad internacional.

En cualquier caso, las observaciones previas no contradicen el hecho de que la intervención de otros sujetos en el comentado orden internacional ha supuesto una intensificación del poliformismo de la subjetividad

19 Cfr. Carpizo, J., "La Soberanía del pueblo en el Derecho interno y en el internacional”, REP, núm. 28, 1982, p. 205.

20 En este sentido, el párrafo 7 del artículo 2 de la Carta de la Organización de Naciones Unidas establece que: "Ninguna disposición de esta Carta autorizará a las Naciones Unidas a intervenir en los asuntos que son esencialmente de la jurisdicción interna de los Estados, ni obligará a los Miembros a someter dichos asuntos a procedimientos de arreglo conforme a la presente Carta; pero este principio no se opone a la aplicación de las medidas coercitivas prescritas en el Capítulo VII". Sobre esta disposición, la práctica de las Naciones Unidas no ha sido muy clara, puesto que ha existido cierta indeterminación en torno al concepto de “intervención”. Martín Martínez considera que la doctrina concibe este artículo como un precepto legal fundamental a la hora de determinar la compatibilidad entre la protección de la soberanía y la defensa del interés de la comunidad internacional. Véase Martín Martínez, M. M., "Scope and limits of the cession of State's powers to the United Nations", National Sovereignty and International Organizations, La Haya, Kluwer Law International, 1996, p. 94.

21 Así se puso de relieve en el referido asunto Wimbledon. Véase supra nota al pie 16. 
Esta revista forma parte del acervo de la Biblioteca Jurídica Virtual del Instituto de Investigaciones Jurídicas de la UNAM

internacional, ${ }^{22}$ lo cual, entre otras cuestiones, supone la cristalización de la idea del fin de la soberanía como elemento limitador. ${ }^{23}$

De esta manera, resulta conveniente retrotraerse al término de la Segunda Guerra Mundial, tras la cual no sólo surgieron nuevos Estados, sino que además apareció y fructificó el proceso de descolonización, advirtiéndose a su vez el protagonismo inusitado que nuevas organizaciones empezaban a adquirir en el ámbito de la comunidad internacional. La conjunción de todos estos factores influyó en la nueva configuración de aquélla, anteriormente marcada — casi con carácter exclusivo- por la actuación estatal.

Además de lo anterior, es necesario recalcar que la comunidad internacional, en las últimas décadas, se ha globalizado y se ha integrado de forma continuada y constante. Por lo anterior, debe indicarse que es en el referido escenario donde no sólo los Estados cumplen un papel fundamental, sino que otros actores como las organizaciones internacionales, así como las multinacionales e, incluso, los individuos, gozan de un gran protagonismo, haciendo más compleja la articulación de las relaciones internacionales. ${ }^{24}$

En definitiva, el sistema legal supranacional ha evolucionado de forma significativa, al reflejar la naturaleza cambiante de la sociedad internacional conforme a la cual se advierte el creciente e indiscutible rol de otros actores - ya no sólo los Estados — que intervienen en la misma.

Consecuentemente, abordaremos a continuación de qué modo y con qué impacto los nuevos sujetos tienen su propio acomodo dentro del ordenamiento jurídico internacional; un ordenamiento en el que la cuestión relativa a la subjetividad no se deduce exclusivamente de la soberanía como mecanismo de atribución de derechos y obligaciones, sino que es también el resultado de otras circunstancias o vicisitudes. ${ }^{25}$

22 Véase Díez de Velasco, M. et al., "El concepto de derecho internacional público", Instituciones de derecho internacional público, Madrid, Tecnos, 2015, pp. 78 y 79.

23 Véase Yturriaga Barberán, J. A., "La Organizaciones Internacionales y la soberanía de los Estados”, Revista de Estudios Jurídicos, Madrid, núm. 135-136, 1964, p. 93.

24 Al final del siglo XX, The Yearbook of International Organization informaba de que existían más de 922 organizaciones intergubernamentales y 9988 organizaciones no gubernamentales internacionales.

25 Véase Remiro Brotóns, A. et. al, op. cit., p. 93. 
Esta revista forma parte del acervo de la Biblioteca Jurídica Virtual del Instituto de Investigaciones Jurídicas de la UNAM

\title{
III. LOS OTROS CONSAGRADOS SUJETOS NO ESTATALES
}

\author{
DE LA REGULACIÓN INTERNACIONAL
}

A raíz de las manifestaciones anteriores, no cabe duda de que la sociedad internacional presenta una naturaleza fundamentalmente interestatal. Sin embargo, y como ya quedó apuntado, debe destacarse la actuación de otros actores que participan en las actuales y complejas relaciones internacionales ejerciendo una notable influencia en el marco de las mismas y, por supuesto, generando el consiguiente impacto en el contenido de la propia normativa supranacional. Cabe argumentar que la homogeneidad del sistema internacional del pasado no ha permanecido advirtiendo, en la actualidad, altas dosis de heterogeneidad. De hecho, así quedó reflejado el 11 de abril de 1949, cuando la Corte Internacional de Justicia en el caso relativo a la reparación por daños sufridos al servicio de las Naciones Unidas proclamó la siguiente cuestión:

Los sujetos de derecho, en un sistema jurídico, no son necesariamente idénticos en cuanto a su naturaleza o la extensión de sus derechos; y su naturaleza depende de las necesidades de la comunidad. El desarrollo del derecho internacional, a lo largo de su historia, ha estado influido por las exigencias de la vida internacional y el incremento progresivo de las actividades colectivas de los Estados ha originado ya ejemplos de acción ejercida en el plano internacional por ciertas entidades que no son Estados. ${ }^{26}$

No hay duda de que ha tenido lugar "una diversificación de los sujetos del DI, conservando, no obstante, los Estados su carácter de sujetos originarios de este orden jurídico". ${ }^{27}$ Así, el listado de sujetos de derecho internacional se ha visto ampliado, fruto de las necesidades de la propia comunidad internacional, la cual ha ido asumiendo un mayor número de retos y funciones. ${ }^{28}$

26 Disponible en: http://www.icj-cij.org/homepage/sp/files/sum_1948-1991.pdf.

27 Díez de Velasco, M. et al., op. cit., p. 276.

28 En este sentido, Yturriaga Barberán afirma que: "Hoy todo parece indicar que el Estado no se basta con sus recursos para realizar la función que antes en monopolio cumpliera; el Estado se ve impotente para satisfacer las necesidades y exigencias que a escala mundial, planetaria, tiene planteadas la Humanidad en el momento presente. Se ha producido, en consecuencia, una modificación en el esquema funcional, en la distribución de cometidos 
Esta revista forma parte del acervo de la Biblioteca Jurídica Virtual del Instituto de Investigaciones Jurídicas de la UNAM

En definitiva, quienes ostentan personalidad jurídica internacional ya no sólo son los Estados. ${ }^{29}$

Abandonando, por tanto, la clásica postura reduccionista de la personalidad conforme a la cual los Estados son los únicos sujetos con capacidad para actuar más allá del plano doméstico, debemos tener claro que para ser titular de aquélla es necesario que el sujeto en cuestión no sólo sea "beneficiario de un derecho o estar afectado por una obligación, sino que [además] se requiere una aptitud para hacer valer el derecho ante instancias internacionales o pasar a ser responsable en el plano internacional en caso de violación de la obligación". ${ }^{30}$ Claramente, la citada cualidad parece estar ligada a una legitimidad procesal activa y pasiva. ${ }^{31}$ En cualquier caso, lo relevante es apreciar o no dicha "aptitud" en la medida en que si no puede advertirse la existencia de la misma, estaremos, como mucho, ante un actor influyente en el ámbito de las relaciones internacionales que, no obstante, adolece de la comentada personalidad jurídica.

Al hilo de las consideraciones anteriores, conviene tener presente que la referida capacidad puede ser más o menos amplia en función del sujeto que sea objeto de análisis. Así lo confirma la Corte Internacional de Justicia, en el reiterado asunto de 1949, cuando señala que: "un Estado posee la totalidad de derechos y deberes internacionales, [frente a] los derechos y deberes de una entidad como la Organización, [los cuales] han de depender de los propósitos y funciones de ésta, tal como son enunciados o están implícitos en sus textos constitutivos y desarrollados en la práctica”. De alguna manera, se percibe que frente a los Estados, los cuales se erigen como sujetos plenos y necesarios del derecho internacional, existen otros con una personalidad limitada que tienen posibilidad de intervenir en la elaboración de normas supranacionales, de erigirse como sujetos responsables en la esfera internacional y de reclamar sus derechos conforme a los mecanismos

sociales que anteriormente existía entre el Estado y la sociedad internacional”. Cfr. Yturriaga Barberán, J. A., op. cit., p.102.

29 Cfr. Díez de Velasco, M., et al., op. cit., p. 275.

30 Ibidem, pp. 276 y 277.

31 No obstante, no todo el mundo secunda la referida visión en torno a la personalidad jurídica internacional, tal y como se observa a continuación: "the ability to bring an international claim should appropriately be regarded as a possible consequence of, but not a prerequisite to, international legal personality”. Cfr. Murray, D., Human Rights Obligations of Non-State Armed Groups, Oregon, Hart, 2016, p. 47. 
Esta revista forma parte del acervo de la Biblioteca Jurídica Virtual del Instituto de Investigaciones Jurídicas de la UNAM

previstos por dicha regulación. Y, como era de esperar, las organizaciones internacionales juegan, en este caso, un papel esencial.

Efectivamente, y en consonancia con la observación previa, debemos afirmar que en la actualidad no se cuestiona la personalidad jurídica internacional de las organizaciones internacionales, si bien es cierto que existe cierta duda en torno al fundamento de la misma. En este orden de ideas, el debate gira en torno a si aquéllas gozan de dicha personalidad de forma objetiva o si es consecuencia de su propio tratado constitutivo. Los que defienden la naturaleza objetiva de su subjetividad sostienen que desde que son creadas gozan del referido atributo.

Tal y como argumenta Vacas Fernández, conforme a esta teoría se deduce que "toda organización internacional tiene de un modo inherente dicha personalidad”. ${ }^{32}$ Frente a esta idea, cabe destacar la posición de aquellos que sostienen que son los propios Estados los que a través del instrumento legal oportuno confieren personalidad jurídica a la organización internacional de turno.

Frente a la anterior disyuntiva, la Corte Internacional de Justicia - en el referido asunto de 1949 — determinó que la Carta de la Organización de las Naciones Unidas otorgaba derechos y obligaciones, los cuales no concordaban con los atribuidos a los Estados en la medida en que el objetivo de aquélla consistía en mantener la paz y la seguridad internacional. De esta manera, se advierte que la personalidad jurídica internacional de las organizaciones no se predica en los mismos términos que la de los Estados. ${ }^{33}$

32 Cfr. Vacas Fernández, F., "Fundamento jurídico internacional; la subjetividad internacional de Naciones Unidas y su sometimiento al Derecho Internacional”, La responsabilidad internacional de Naciones Unidas, Madrid, Dykinson, 2002, p. 78.

33 La afirmación en cuestión se fundamenta en la siguiente declaración emitida por la Corte Internacional en el mencionado asunto de 1949: "la Organización estaba destinada a ejercer funciones y a gozar de derechos que no pueden explicarse más que si la Organización posee en amplia medida personalidad internacional y la capacidad de obrar en el plano internacional. Actualmente constituye el tipo más elevado de organización internacional, y no podría responder a las intenciones de sus fundadores si estuviese desprovista de la personalidad internacional. Se debe admitir que sus miembros, al asignarle ciertas funciones, con los deberes y responsabilidades que les acompañan, la han revestido de la competencia necesaria para permitirle cumplir efectivamente estas funciones... En consecuencia, el Tribunal llega a la conclusión de que la Organización es una persona internacional”. 
Esta revista forma parte del acervo de la Biblioteca Jurídica Virtual del Instituto de Investigaciones Jurídicas de la UNAM

Superada y admitida la subjetividad de las organizaciones internacionales, ${ }^{34}$ resulta de interés traer a colación la personalidad jurídica internacional, si bien limitada, de actores vinculados a la religión ${ }^{35}$ (nos referimos, en este caso, a la Santa Sede, la Cuidad del Vaticano y a la Orden de Malta), así como la de aquellos subsumidos a cierto grado de beligerancia; ${ }^{36}$ en este sentido, aludimos expresamente a los movimientos de liberación nacional, grupos rebeldes o aquellos que se encuentran bajo el ámbito aplicativo del principio de libre determinación de los pueblos. ${ }^{37} \mathrm{Al}$ día de hoy, se admite la subjetividad internacional de los anteriores y, por tanto, su capacidad para ser titulares de derechos y obligaciones en el marco de la regulación internacional. ${ }^{38}$ Ello, en gran medida, se debe a que, tal y como indica Barberis, "la calidad de sujeto no depende de la cantidad de derechos u obligaciones de que una entidad es titular"; ${ }^{39}$ es más, "los sujetos internacionales son muy distintos entre sí y la cantidad de derechos y obligaciones de que son titulares es también muy diversa" ${ }^{40}$ Sea como fuere, el resultado es que las funciones y capacidades de los Estados se ven mermadas como consecuencia de la cooperación interna-

34 Véase Díez de Velasco, M. et al., "El estatuto jurídico de las organizaciones internacionales”, Las organizaciones internacionales, Madrid, Tecnos, 2015, pp. 64 y ss. A este respecto, se pone de relieve que las "reglas propias de cada Organización nos permitirá determinar las competencias internacionales que le han sido atribuidas o que pueden deducirse de las mismas. Del conjunto de estas competencias se extraerá la personalidad jurídica internacional de la que goza cada Organización en concreto”. Ibidem, p. 65. Asimismo, véase Vacas Fernández, F., op. cit., pp. 78 y ss.

35 Véase Barberis, J., "La personalidad jurídica internacional", Los sujetos de derecho internacional, Madrid, Tecnos, 1984, pp. 99 y ss.

36 Conforme al artículo 3o. común a la Convenciones de Ginebra de 1949, se crean "obligaciones y derechos a cargo de entidades que son parte en un conflicto armado no internacional”.

37 A este respecto, debemos indicar que los pueblos no son generalmente titulares de normativa internacional; son, en realidad, objetivo de aquélla. Sin embargo, cabe mencionar a modo de excepción el artículo 3o. de la Declaración de las Naciones Unidas sobre los Derechos de los Pueblos conforme al cual se advierte la posibilidad de que éstos apliquen el principio de libre determinación. Ello, sin duda, les confiere subjetividad internacional, si bien es cierto que se trata de una subjetividad un tanto limitada. Véase Torrecuadrada GarcíaLozano, S., "Definición y subjetividad de los pueblos indígenas en el derecho internacional", Los pueblos indígenas en el orden internacional, Madrid, Dykinson, 2001, p. 52.

38 Véase Díez de Velasco, M., et al., op. cit., pp. 298 y ss.

39 Cfr. Barberis, J., op. cit., p. 26.

$40 \quad$ Ibidem, p. 27. 
Esta revista forma parte del acervo de la Biblioteca Jurídica Virtual del Instituto de Investigaciones Jurídicas de la UNAM

cional y del multilateralismo; fenómenos, ambos, que transforman de forma severa el sistema internacional, antojándose éstos y los demás sujetos como cruciales a la hora de afrontar y abordar las complejidades que surgen en este mundo altamente globalizado e interconectado. ${ }^{41}$

Así pues, puede concluirse que la soberanía ya no se erige como el atributo determinante sobre el que se aprecia o no la personalidad jurídica internacional de un sujeto. En este sentido, la superación del mencionado requisito implica analizarlo como un elemento del pasado; es decir:

incardinarlo en una determinada época histórica y explicarlo en función de cuál fué la sociedad internacional de su tiempo. Se trataría, pues de una historia de la soberanía que haría "pendant" con la historia de la sociedad internacional, del derecho internacional y de la organización internacional, en cuanto forma de estructuración de aquélla. ${ }^{42}$

Se produce, por tanto, un cambio en la configuración inicial de la personalidad jurídica internacional, apreciando la subjetividad en actores no estatales que juegan un papel crucial en el ámbito de la sociedad internacional. De esta manera, cabe recalcar que dicho atributo de la soberanía — insoslayable para los Estados - constituye, para muchos, "una categoría técnica de acusado matiz procesal, que en el aspecto activo comporta la posibilidad de reclamación directa en el plano internacional cuando se es víctima de una violación de derechos, y en el aspecto pasivo implica la posibilidad de sufrir directamente responsabilidad internacional por quebrantamiento de obligaciones". ${ }^{43}$

Sea como fuere, ante los cambios acaecidos, no puede sino vislumbrarse el significativo avance o paso que se ha efectuado en los últimos tiempos con respecto a las afirmaciones contenidas en el caso Lotus, a través del cual se puso de relieve que la regulación supranacional regía "las relaciones internacionales entre Estados independientes", lo que a todas luces resulta una premisa inexacta y alejada de la realidad actual. ${ }^{44} \mathrm{~A}$ raíz de lo anterior, debemos nece-

${ }^{41}$ Cfr. Remiro Brotóns, A., et. al, op. cit., p. 96. En cualquier caso, no debemos olvidar que la sociedad internacional está fundamentalmente dirigida por Estados, pero - y ello es relevante — no sólo éstos son los protagonistas de la misma. Ibidem, p. 97.

42 Cfr. Yturriaga Barberán, J. A., op. cit., p. 88.

43 Cfr. Pastor Ridruejo, J. A., "El individuo en el derecho internacional”, Curso de derecho internacional público y organizaciones internacionales, Madrid, Tecnos, 2016, pp. 730 y 731.

44 Véase Remiro Brotóns, A. et. al, op. cit., p. 93. 
Esta revista forma parte del acervo de la Biblioteca Jurídica Virtual del Instituto de Investigaciones Jurídicas de la UNAM

sariamente analizar y detenernos en la situación de los individuos en la medida en que "el derecho internacional contemporáneo... se está humanizando, socializando y, en definitiva, moralizando, y ha añadido a las funciones relacionales y competenciales la del desarrollo integral de los individuos y pueblos mediante una cooperación que en muchos casos es institucionalizada"; ${ }^{45}$ pudiendo deducir, quizá, ante este nuevo panorama, la personalidad jurídica internacional de las personas tanto físicas como jurídicas.

\section{EL COMPLEJO ESTATUS DE LAS PERSONAS FÍSICAS}

Y JURÍDICAS EN EL ORDEN LEGAL INTERNACIONAL ACTUAL

\section{La persona física en el derecho internacional contemporáneo}

A raíz de las premisas anteriores, no hay duda de que la comunidad internacional evoluciona y se transforma, lo que se traduce en la ampliación del número de actores que intervienen en ella. ${ }^{46} \mathrm{Si}$ esta afirmación se combina con lo apuntado anteriormente acerca del innegable proceso de humanización al que ha quedado sometido el derecho internacional contemporáneo, no debe resultarnos ajeno el debate que se plantea acerca de si las personas tanto físicas como jurídicas disponen o no de personalidad jurídica internacional. Esta disquisición debe examinarse a través de la opinión emitida por la Corte Internacional de Justicia, en el señalado informe, relativo a la reparación de los daños sufridos al servicio de las Naciones Unidas, conforme al cual "los sujetos de derecho, en un sistema jurídico, no son necesariamente idénticos en cuanto a la naturaleza o a la extensión de sus derechos; y su naturaleza depende de las necesidades de la comunidad".

De esta forma, parece factible afirmar que el grado de subjetividad varía y que su incidencia en el plano supranacional difiere entre los distintos sujetos existentes. Ello cobra gran relevancia a la hora de valorar la repercusión que ésta tiene cuando se analiza bajo el prisma de entidades no estatales en la medida en que, como se ha dicho, se admiten diferentes categorías de aquélla.

45 Cfr. Pastor Ridruejo, J. A., op. cit., p. 191.

46 Véase Barberis, J., op. cit., p. 27. 
Esta revista forma parte del acervo de la Biblioteca Jurídica Virtual del Instituto de Investigaciones Jurídicas de la UNAM

Partiendo de las premisas anteriores, resulta acuciante resolver la incógnita previamente referida: ¿disponen las personas físicas de la citada personalidad? A este respecto, conviene indicar que éstas son receptoras de una cuantiosa regulación internacional, pero ello obviamente no confiere, sin más, la mencionada personalidad. Es preciso, como ya hemos adelantado, dirimir en un primer momento si los individuos tienen o no capacidad para entablar una acción de reclamación, puesto que, en caso afirmativo, dispondrán, como ya adelantamos en su momento, de una subjetividad internacional activa. A la luz de todas estas consideraciones, debemos resaltar que, cuando la conducta infractora es atribuible a un Estado, no es posible que la persona física perjudicada se dirija a la Corte Internacional de Justicia, tal y como determina el artículo 34(1) de su Estatuto. ${ }^{47}$

Sin embargo, hay que admitir que el locus standi de aquéllos se ha contemplado ante múltiples órganos judiciales de carácter supranacional. ${ }^{48}$ Así, a modo de ejemplo, cabe destacar la relevancia de la Corte de Justicia Centroamericana, la cual posibilitó que los individuos tuvieran acceso a una jurisdicción de naturaleza internacional. ${ }^{49}$ En términos similares, debemos referirnos a la Convención Americana de Derechos Humanos y, más concretamente, al artículo 44 del mencionado instrumento, en virtud del cual se le reconoce al individuo su capacidad para dirigirse a la instancia judicial de turno. Es más, la referida disposición legal convirtió "el derecho de petición individual... [en] mandatorio, de aceptación automática por los Estados ratificantes". ${ }^{50}$ Sin embargo, debe indicarse que el derecho de petición contenido en el citado artículo implica necesariamente la actuación de la Comisión Interamericana de Derechos Humanos, la cual, una vez constatada la violación — en su caso_ de un determinado derecho,

47 La redacción del mencionado artículo fue en su día objeto de crítica precisamente por capacitar únicamente a los Estados a participar en un juicio ante la Corte Internacional de Justicia. Cfr. Cançado Trindade, A. A., "La persona humana como sujeto del derecho internacional: avances de su capacidad jurídica internacional en la primera década del siglo XXI”, Revista IIDH, vol. 46, 2007, p. 284.

48 Véase Pastor Ridruejo, J. A., op. cit., pp. 198 y ss.

49 En palabras de Cançado Trindade, el rasgo fundamental de la mencionada Corte de Justicia Centroamericana consistió en ampliar al máximo el ámbito de su jurisdicción, siendo "pionera al otorgar acceso directo, para interponer demandas, no sólo a los Estados sino también a los individuos, contribuyendo así a la consagración de éstos como sujetos del derecho internacional”. Cfr. Cançado Trindade, A. A., op. cit., p. 285.

50 Ibidem, p. 302. 
Esta revista forma parte del acervo de la Biblioteca Jurídica Virtual del Instituto de Investigaciones Jurídicas de la UNAM

concluirá si el asunto en cuestión se eleva o no a la Corte Interamericana de Derechos Humanos. De esta manera, "al individuo se le dota de amplias facultades y capacidades procesales. Pero una vez que la Comisión emite su informe, pierde el caso y se encuentra a la espera de que ésta plantee o no la demanda ante la Corte. Si se llega a instaurar el caso ante la Corte, el peticionario inicial es desplazado, o al menos esa parece ser la intención del sistema consagrado en la CADH". ${ }^{51}$

En línea con lo anterior, debemos traer a colación el Convenio Europeo de los Derechos Humanos y de las Libertades Fundamentales de 1950 en la medida en que supuso, entre otras cuestiones, la aprobación del Protocolo número 11 , conforme al cual se introdujo la posibilidad de que las personas presentaran la correspondiente demanda ante el Tribunal Europeo de Derechos Humanos. ${ }^{52}$ De esta manera, se permitió — de acuerdo con lo estipulado en el artículo 34 del mencionado Protocolo- a los ciudadanos de a pie recurrir a un tribunal internacional, independientemente de que la parte infractora fuera un Estado.

En definitiva, la comentada herramienta "ha modificado en profundidad el sistema de garantía y control del Convenio Europeo de Derechos Humanos y ha introducido importantísimas innovaciones que contribuirán a incrementar la eficacia de los medios de protección". ${ }^{33}$ Además, al margen de lo recien-

51 Cfr. Rosas Castañeda, J. A., "Hacia el jus standi del individuo en el procedimiento ante la Corte Interamericana de Derechos Humanos", Revista CEJIL, núm. 3, 2007, p. 83. De esta manera, se entiende a la perfección la razón por la que se está abogando, por un lado, por el abandono del locus standi de los individuos y, por otro, por el reconocimiento de su ius standi. Así, se posibilitaría un acceso directo a la Corte Interamericana de Derechos Humanos.

52 Disponible en: http: / / www.famp.es/racs/ramlvm/NORMATIVA\%20UE/DOC\%202.pdf. En relación con el contenido del referido Protocolo, debemos indicar que muchos fueron los que lo alabaron, argumentando fundamentalmente la siguiente cuestión: "el individuo pasó así a tener, finalmente, acceso directo a un tribunal internacional (jus standi), como verdadero sujeto - y con plena capacidad jurídica - del derecho internacional de los derechos humanos. Ibidem, p. 297. En cualquier caso, no debe dejar de mencionarse el Protocolo número 14 conforme al cual, con ánimo de descargar de trabajo al saturado Tribunal, se introdujeron ciertas limitaciones en torno a las posibles causas de inadmisibilidad de un asunto.

53 Cfr. Salado Osuna, A., "El protocolo de enmienda número 11 al Convenio Europeo de Derechos Humanos", Revista de Instituciones Europeas, vol. 21, núm. 3, 1994, p. 963. Tal y como apunta Drzemczewski, si bien es cierto que el Protocolo número 11 facilita a los individuos la posibilidad de acudir a la Corte sin ningún tipo de restricción, conviene hacer referencia al Protocolo número 9 en la medida en que trató de introducir, con anterioridad, una serie de cambios que apuntaban en la dirección del anterior. Véase Drzemczewski, A., 
Esta revista forma parte del acervo de la Biblioteca Jurídica Virtual del Instituto de Investigaciones Jurídicas de la UNAM

temente comentado, hay que recalcar que los funcionarios que integran las organizaciones internacionales quedan sujetos a la regulación interna de la misma; una manifestación más de la personalidad jurídica internacional de naturaleza activa que poseen los individuos.

Siendo conscientes de las implicaciones que tienen las aseveraciones del párrafo anterior, resulta prioritario determinar si los individuos ostentan también una personalidad jurídica de naturaleza pasiva. Evidentemente, las violaciones de normativa supranacional generan una responsabilidad clara en caso de que el infractor de la misma sea un Estado. Sin embargo, no ocurre lo mismo cuando se examina la responsabilidad de los anteriores.

Sea como fuere, al referirnos a los crímenes internacionales, advertimos la existencia de dicha responsabilidad en la medida en que estos ilícitos se configuran como "acciones que atentan contra la humanidad propiciamente «crimina iuris Gentium»". ${ }^{54}$ Así, cuando se persiguen delitos que afectan al conjunto de los intereses de la comunidad internacional, es posible apreciar la responsabilidad de los individuos. Ello quedó reflejado, en un primer momento, en los procesos jurisdiccionales que tuvieron lugar tras el término de la Segunda Guerra Mundial, en Núremberg, conforme a los cuales se emitieron sentencias condenatorias en contra de dirigentes, funcionarios y colaboradores del régimen nacionalsocialista debido a su implicación en la perpetración de delitos de envergadura. ${ }^{55}$

Los citados juicios representaron, por vez primera, la oportunidad de proteger la normativa relativa a los derechos humanos de una forma directa, al dar la posibilidad de juzgar a los que los habían socavado durante el referido conflicto bélico. ${ }^{56}$ En un contexto más actual, debemos destacar la valiosa actuación de la Corte Penal Internacional — si bien es cierto que

"The European Human Rights Convention: Protocol No. 11 entry into force and first year of application”, Human Rights Law Journal, núm. 21, 2000, p. 360.

${ }_{54}$ Cfr. Riquelme Ortiz, C. "Los crímenes internacionales y los mecanismos de sanción en América Latina”, en Boeglin, Nicolás et al. (eds.), La Corte Penal Internacional: Una perspectiva latinoamericana, San José, Upeace University Press, 2012, p. 2.

55 En este sentido, conviene traer a colación el artículo 6 del Estatuto de Londres del Tribunal Militar Internacional, suscrito en 1945, conforme al cual se estipuló que el citado tribunal tenía la facultad de juzgar crímenes graves cometidos por los "principales criminales de guerra del Eje Europeo”.

56 Véase Ratner, S. R. y Abrams, J. S., "The Progeny of Nuremberg: International Criminal Tribunals", Accountability for Human Right Atrocities in International Law, Nueva York, Oxford University Press, 2001, pp. 343 y 344. 
Esta revista forma parte del acervo de la Biblioteca Jurídica Virtual del Instituto de Investigaciones Jurídicas de la UNAM

cuenta con ciertas y decepcionantes limitaciones en su modus operandi- ${ }^{57}$ en la medida en que se trata de un órgano judicial que tiene encomendada de forma permanente la investigación de crímenes de envergadura como, por ejemplo, los crímenes contra la humanidad o el genocidio. Así pues, "el individuo, y no ya sólo el Estado, puede incurrir en responsabilidad internacionalmente exigible cuando incumple obligaciones del DI Humanitario dentro de comportamientos tipificados como delitos contra el derecho de gentes". ${ }^{58}$

Como ya advirtió en su momento la Corte Interamericana de Derechos Humanos, en la Opinión Consultiva del 9 de diciembre de 1994, sobre la Responsabilidad Internacional por Expedición y Aplicación de Leyes Violatorias de la Convención, "el derecho internacional puede conceder derechos a los individuos e, inversamente, determinar que hay actos u omisiones por los que son criminalmente responsables desde el punto de vista de ese derecho... [. Ello] representa una evolución de la doctrina clásica de que el derecho internacional concernía exclusivamente a los Estados".

A raíz de las consideraciones anteriores, conforme a las cuales se advierte que el individuo ostenta, en el orden legal supranacional, una legitimación de carácter activo y pasivo, parece plausible afirmar o, al menos, no resulta tan irritante discutir — como probablemente sucediera en el pasado- que, quizá, hasta cierto punto el individuo dispone de personalidad jurídica internacional. Ello, sin duda, supone un cambio revolucionario con respecto a otros momentos históricos en los que los creadores del orden internacional, los Estados, copaban todo protagonismo, eclipsando a los demás actores que, de un modo u otro, intervenían en el ámbito de la comunidad internacional.

57 Son numerosas las limitaciones que a este respecto pueden traerse a colación. A modo ilustrativo debe señalarse que la actuación de la Corte Penal Internacional queda condicionada, conforme al artículo 12 del Estatuto de Roma, a que los ilícitos graves "hayan sido cometidos por nacionales de los Estados firmantes del citado Estatuto y/o que éstos hayan tenido lugar en dichos Estados parte si bien, de conformidad con el apartado tercero del citado precepto legal, la Corte podrá en ciertas situaciones juzgar hechos delictivos relevantes que atañen a un Estado no parte siempre que haya decidido aceptar puntualmente su competencia”. Cfr. Hellman Moreno, J., “¿Corte Penal Internacional versus justicia universal?”, Revista Jurídica de la Universidad del Norte, núm. 6, 2013, p. 129. Asimismo, véase Ratner, S. R., y Abrams, J. S., op. cit., pp. 212 y ss.

58 Cfr. Remiro Brotóns, A., et al., op. cit., p. 1239. 
Esta revista forma parte del acervo de la Biblioteca Jurídica Virtual del Instituto de Investigaciones Jurídicas de la UNAM http://www.juridicas.unam.mx/ https://biblio.juridicas.unam.mx/bjv https://revistas.juridicas.unam.mx/ DOI: http://dx.doi.org/10.22201/iij.24487872e.2018.18.12106

Al hilo de lo anterior, cobran relevancia las aseveraciones vertidas por Cançado Trindade, quien señala que

el reconocimiento de la personalidad jurídica del individuo en el plano internacional operó como respuesta a una necesidad de la comunidad internacional. Aunque el escenario internacional contemporáneo sea enteramente distinto del de la época de los llamados "fundadores" del derecho internacional (nadie lo negaría), que propugnaron por una civitas maxima regida por el derecho de gentes, la aspiración humana permanece la misma, o sea, la de la construcción de un ordenamiento internacional aplicable tanto a los Estados (y organizaciones internacionales) como a los individuos, de conformidad con ciertos estándares universales de justicia... La consagración de la personalidad jurídica internacional de la persona humana representa una verdadera revolución jurídica, que viene a dar un contenido ético a las normas tanto del derecho público interno como del derecho internacional. ${ }^{59}$

Por consiguiente, todo indica que la personalidad jurídica internacional del individuo es fruto de un proceso de humanización al que se ha visto sometida, recientemente, la regulación internacional. Siendo así las cosas, no nos queda otro remedio que superar las concepciones clásicas de dicha disciplina, adaptándola a la nueva realidad y admitiendo — sin remilgos aunque con ciertas limitaciones - la titularidad jurídica internacional del ser humano, tal y como se afirma a continuación: "la titularidad jurídica internacional de los individuos es hoy una realidad irreversible, y el ser humano irrumpe, aún en las condiciones más adversas, como sujeto último del derecho tanto interno como internacional, dotado de plena capacidad jurídico-procesal”. ${ }^{60}$

En cualquier caso, debe indicarse que, de acuerdo con algunos autores, el cambio que ha sufrido el ordenamiento jurídico internacional no ha mo-

59 Cfr. Cançado Trindade, A. A., op. cit., pp. 278 y 279.

$60 \mathrm{Ibidem}, \mathrm{p} .328$. Hay más autores que también sostienen la gran repercusión que ha tenido para el derecho internacional su sometimiento a un proceso de "humanización”. Según éstos, ello ha supuesto una "redefinición del tratamiento del individuo por el ordenamiento jurídico internacional, ya no sólo como objeto (beneficiario de derechos o destinatario de cargas), sino como sujeto de derecho internacional: en su expresión sustancial, dotándolo de derechos y obligaciones directamente conferidos; y en su expresión procesal, dotándolo de legitimación procesal para iniciar procedimientos ante órganos supranacionales a través del derecho de petición individual”. Cfr. Rosas Castañeda, J. A., op. cit., p. 82. 
Esta revista forma parte del acervo de la Biblioteca Jurídica Virtual del Instituto de Investigaciones Jurídicas de la UNAM

dificado su verdadera esencia; es más, las referidas alteraciones acaecidas — desde el prisma de aquéllos — son realmente fruto del compromiso de los Estados para con las obligaciones que éstos mismos contraen de forma positiva en el ámbito supranacional. ${ }^{61}$

En este sentido, Chinchón Álvarez indica que los Estados adoptan "las medidas necesarias en sus ordenamientos internos para hacer posible el enjuiciamiento y castigo de los responsables de actos contrarios al derecho internacional — cuyo incumplimiento comprometería su responsabilidad internacional_-". ${ }^{62}$ No obstante, el citado autor considera que el creciente y progresivo deber de cumplimiento estatal para con el derecho internacional no es sino consecuencia del desarrollo y la relevancia de las normas supranacionales ligadas al ámbito de los derechos humanos. ${ }^{63}$

Sea como fuere, independientemente de si los citados cambios han afectado más o menos a la esencia del orden legal internacional, debemos apuntar que gran parte de la doctrina se muestra a favor de la subjetividad de los individuos ${ }^{64}$ siempre advirtiendo que la plenitud de aquélla la ostentan úni-

61 Así las cosas, debe traerse a colación la aseveración de Chinchón Álvarez: "lo cierto es que aunque el derecho internacional reconoce derechos e impone obligaciones a los particulares, ello es siempre el resultado de un acuerdo entre Estados; siendo que tanto la responsabilidad de cumplir esos acuerdos, como la responsabilidad en caso de incumplimiento, así como los mecanismos establecidos para hacer efectivas una u otra, corresponden a los Estados, salvo en aquellos casos en que éstos han convenido otras posibilidades, alternativas o vías". Cfr. Chinchón Álvarez, J., "Responsabilidad internacional del individuo y responsabilidad internacional del Estado: encuentros y desencuentros en torno a la figura de los crímenes de derecho internacional", Protección internacional de derechos humanos y Estado de derecho, Bogotá, Grupo Editorial Ibáñez, 2009, p. 554.

62 Ibidem, p. 555.

63 Véase Chinchón Álvarez, J., op. cit., p. 555.

64 Evidentemente, muchos otros autores se manifiestan en sentido contrario, argumentando que no sólo no es posible afirmar la personalidad jurídica internacional del individuo, sino que además el debate es contraproducente en la medida en que da lugar a un debate estéril que genera fundamentalmente confusión. Así lo pone de relieve Orakhelashvili cuando afirma lo siguiente: "In every case when international criminal responsibility is imposed on the individual, it appears that acts that are committed by the individual are not expected to be punished within one or another national legal order. If the State concerned is able and willing to fulfil its international obligations with respect to punishment of persons committing crimes against peace and security of mankind, an individual is not to be punished through direct application of international law". Cfr. Orakhelashvili, A., "The Position of the Individual in International Law”, CaliforniaWestern International Law Journal, vol. 31, núm. 2, 2000, p. 36. 
Esta revista forma parte del acervo de la Biblioteca Jurídica Virtual del Instituto de Investigaciones Jurídicas de la UNAM

camente los Estados. ${ }^{65}$ Así, Lauterpacht, revisando el trabajo realizado por Oppenheim, puso de relieve que "the various developments since two World Wars no longer countenance the view that, as a matter of positive law, States are the only subjects of international law. In proportion as the realisation of that fact gains ground, there must be an increasing disposition to treat individuals, within a limited sphere, as subjects of International Law" ${ }^{66}$ También resultan interesantes las observaciones vertidas por Jesheck, quien argumenta a favor de la personalidad jurídica del individuo. ${ }^{67} \mathrm{Y}$, por supuesto, lo mismo sucede con las reveladoras aseveraciones de Cassese, quien admite que el orden legal internacional aboga hacia una civitas maxima, a la cual define del siguiente modo: "a human commonwealth encompassing individuals, States, and other aggregates cutting across boundaries of States". ${ }^{68}$

Teniendo claro todo lo anterior, nos surge el siguiente interrogante: ¿es posible establecer un paralelismo entre la persona física y jurídica en lo que a personalidad jurídica internacional se refiere? En otras palabras, a raíz de la afirmación anterior, conforme a la cual se pone de relieve que el ser humano ostenta la condición de sujeto en el plano de la regulación internacional, ¿es posible identificar este mismo "rasgo" con respecto a las corporaciones? Debido a lo complejo de la cuestión, esta ardua y compleja pregunta será debidamente abordada y resuelta en el punto siguiente con todas las implicaciones que puedan suscitarse al respecto.

\section{La persona jurídica en el derecho internacional contemporáneo}

Como ya vimos en el apartado anterior, parece claro que los individuos gozan de cierta consideración en el ámbito de la regulación internacional, pero ello no significa que pueda establecerse, sin más, una analogía con respecto a las personas jurídicas. Siendo conscientes de lo anterior, debemos indicar que sujetos importantes en el ámbito de la comunidad internacio-

65 Véase Cassese, A., Los derechos humanos en el mundo contemporáneo, Barcelona, Ariel, 1993, p. 235.

66 Cfr. Oppenheim, L., International Law: a treatise 636, 8a. ed., H. Lauterpacht, 1955.

67 Véase Jesheck, H. H., "The General Principles of International Criminal Law Set out in Nuremberg, as Mirrored in the ICC Statute”, Journal of International Criminal Justice, núm. 2, 2004 , p. 43.

68 Cfr. Cassese, A., International Law, 2a. ed., Oxford University Press, 2005, p. 217. 
Esta revista forma parte del acervo de la Biblioteca Jurídica Virtual del Instituto de Investigaciones Jurídicas de la UNAM

nal, como la Organización de las Naciones Unidas, parecen haber avivado el debate en cuestión. En este orden de ideas, debe traerse a colación el informe auspiciado por John Ruggie, ex representante especial del secretario general para la cuestión de los derechos humanos y las empresas transnacionales y otras empresas, realizado en 2011, conforme al cual se puso de relieve la particular y necesaria sinergia que debe existir entre las personas jurídicas y la regulación relativa a los derechos humanos. ${ }^{69}$

En cualquier caso, pese a que pueda considerarse - como ya veremosun documento de cierto interés, su eficacia se ve seriamente mermada al tratarse de una herramienta más del soft law, lo que ha llevado a muchos autores a incidir en la idea relativa a que "las empresas carecen por el momento de la condición de sujetos de responsabilidad (jurídica) internacional pasiva, y en su lugar únicamente parecen estar llamadas a una eventual responsabilidad social voluntariamente asumida". ${ }^{70}$

Al hilo de las consideraciones previas, debemos apuntar que, bajo ningún concepto, el reconocimiento de la personalidad internacional de las corporaciones es algo unánimemente aceptado, si bien es cierto que debe admitirse la existencia de un debate que, en estos momentos, se encuentra en su punto álgido; pudiendo ser, quizá, un preludio de nuevos y desafiantes cambios. En el referido contexto, conviene recordar — una vez más — que la sociedad internacional ya no presenta un exclusivo carácter estatal en la medida en que son muchos los actores que influyen y determinan las actuales y complejas relaciones internacionales. Si ello se combina con el hecho de que la regulación internacional contemporánea se ha visto sometida a un indubitado proceso de humanización, cabe apreciar una sustancial alteración de su "fisonomía", lo cual apoya la idea de reconocer una personalidad jurídica internacional amplia a favor de ciertos actores no estatales.

Siendo así las cosas, no nos extraña la discusión que surgió, en su día, en torno a si las personas físicas eran o no sujetos, como tampoco la actualmente existente en materia de personas jurídicas. En estos momentos, como ya hemos dicho, muchos son los autores que se han decantado — no sin afrontar numerosos obstáculos - por atribuir personalidad jurídica in-

69 Véase infra pp. 18 y ss.

70 Cfr. García Mosquera, M., "La personalidad jurídica de empresas transnacional como requisito de la responsabilidad penal del art. 31 bis CP”, Estudios Penales y Criminológicos, vol. 33, 2013, p. 326. 
Esta revista forma parte del acervo de la Biblioteca Jurídica Virtual del Instituto de Investigaciones Jurídicas de la UNAM http://www.juridicas.unam.mx/ https://biblio.juridicas.unam.mx/bjv https://revistas.juridicas.unam.mx/ DOI: http://dx.doi.org/10.22201/iij.24487872e.2018.18.12106

ternacional al individuo; $;^{71}$ una situación que, como argumentábamos, no es extrapolable al ámbito de las personas jurídicas, donde se perciben mayores reticencias y dificultades. Pese a ello, en este escenario objeto de análisis parece reinar cierta confusión, especialmente si tomamos en consideración estrategias ideadas por sujetos internacionales, como la diseñada por la Organización de las Naciones Unidas, puesto que si bien es cierto que no reclaman directamente cambios en el sistema legal internacional, ni se refieren expresamente a la subjetividad internacional de aquéllas, parece haberse alimentado la controversia en cuestión sobre la base de ideas pragmáticas conforme a las cuales se indica, con ahínco, lo apropiado de someter a las empresas bajo el ámbito aplicativo de la regulación internacional en materia de derechos humanos. ${ }^{72}$

Es posible, como veremos en el punto siguiente, que la anterior maniobra sirva de acicate — y de ahí lo relevante de la misma - para la consagración de una concepción amplia de la civitas maxima ${ }^{73}$ que rompa, frontalmente, con la concepción clásica de la subjetividad internacional.

71 Un aspecto esencial que ha modificado la opinión de muchos autores ha sido el reconocimiento de la capacidad de actuación por parte de los individuos ante instancias judiciales internacionales, tal y como se declara a continuación: "the case for asserting the legal personality of the individual gained strength as individuals were granted access in a number of instances to claim their rights directly before international tribunals". Cfr. Duruigbo, E., "Corporate Accountability and Liability for International Human Rights Abuses: Recent Changes and Recurring Challenges”, Northwestern Journal of International Human Rights, vol. 6, núm. 2, 2008, p. 237.

72 Véase Pentikäinen, M., "Hanging International «Subjectivity» and Rights and Obligations under International Law-Status of Corporations”, Utrecht Law Review, vol. 8, 2012, p. 150 .

73 En este sentido, debe traerse a colación a Kelsen en la medida en que su concepto de civitas maxima tiene una fuerte repercusión en el ámbito de la regulación internacional al admitir la superioridad de dicha normativa con el propósito de asegurar la paz y evitar, a su vez, el imperialismo. Véase Kelsen, H., Pure Theory of Law, trad. por Max Knight, The Lawbook Exchange, LTD., 2008, p. 249. De lo anterior, además, puede deducirse una interesante idea: "Kelsen avanza la propuesta conclusiva de una «revolución de la conciencia cultural» en sentido globalista y cosmopolita. Se trata de un auténtico programa de política del derecho, que propugna una evolución de la comunidad jurídica internacional desde su condición «primitiva», impuesta por el dogma de la soberanía estatal, a una organización global de la humanidad”. Cfr. Zolo, D., "El globalismo judicial de Hans Kelsen”, Rivista di filosofia del diritto internazionale e della politica globale, 2007, disponible en: http: / / www.juragentium.org/topics / thil/es/kelsen.htm\#*. Como ya apuntamos, otros autores también se han referido al concepto de civitas maxima. Véase supra nota al pie 59. 
Esta revista forma parte del acervo de la Biblioteca Jurídica Virtual del Instituto de Investigaciones Jurídicas de la UNAM

Sea como fuere, la opinión predominante — como ya se señaló - es reacia a aceptar la situación anterior. La mayoría sostiene que no todas las entidades que tienen capacidad para participar e influir en las relaciones internacionales contemporáneas deben ser consideradas como personas jurídicas internacionales. Subrayan, además, que la actuación de éstas no conlleva intervención jurídica alguna. ${ }^{74}$ Asimismo, arguyen que estar en posesión de derechos y obligaciones no es motivo para ejercer y, por tanto, ser titular de la referida subjetividad; en línea con lo anterior, no son pocos los que destacan que es necesario ser capaz de crear e implementar una regulación supranacional y, para ello, es crucial advertir algún elemento de carácter público que trascienda de los meros intereses privados. ${ }^{75}$

Evidentemente, hay posturas que no se encuentran tan "encorsetadas" y, por ende, abiertas a cambios, al admitir — como explicamos - que si bien los Estados disponen de una subjetividad plena, las organizaciones internacionales y las corporaciones, así como los individuos, son titulares de una subjetividad de carácter parcial. ${ }^{76}$ Ello permite la configuración de nuevas situaciones en las que las personas jurídicas podrían tener un efectivo protagonismo bajo el prisma de la regulación internacional.

Asimismo y en línea con lo anteriormente expuesto, ciertos autores se han alejado de forma radical de la comentada concepción clásica y sostienen que el individuo debe constituirse, conforme a la máxima ex persona ius oritur, como la piedra angular sobre la cual la sociedad internacional debe descansar. ${ }^{77}$ Posiciones como esta última son las que pueden trasladarse, de algún modo, al ámbito de estudio de las corporaciones en la medida en que su planteamiento conlleva cambios en la configuración tradicional de la per-

74 Véase Nowrot, K., "New Approaches to the International Legal Personality of Multinational Corporations: Towards a Rebuttable Presumption of Normative Responsibility”; artículo entregado en "Geneva Reasearch Forum on International Law" y organizado por la European Society of International Law, 2005, p. 4.

75 Véase Duruigbo, E., op. cit., p. 241.

76 Ibidem, p. 239. En línea con lo expuesto, cabe traer a colación la siguiente afirmación: "while states have the status of primary subjects of international law with the most extensive capacities (full legal capacity), the «subjectivity» of international organisations is limited and determined by the powers vested in them. The scope of this «subjectivity» does give rise to various interpretations". Cfr. Pentikäinen, M., op. cit., p. 146.

77 Véase Domingo, R., Legal principles of Global Law, Estados Unidos, Cambridge University Press, 2010, p. 187. 
Esta revista forma parte del acervo de la Biblioteca Jurídica Virtual del Instituto de Investigaciones Jurídicas de la UNAM

sonalidad jurídica internacional, posibilitando a actores distintos de los Estados, como las empresas, a ser titulares de aquélla; si bien es cierto que, en el contexto empresarial, las circunstancias son muy distintas a las existentes en otros escenarios.

Siendo conscientes de las diferentes opiniones existentes en la materia, resulta extremadamente relevante examinar la reciente sentencia dictada en Holanda por el Tribunal de Apelaciones de Den Bosch, conforme a la cual el director de operaciones de varias compañías que operaban en Liberia, Guus Kouwenhoven, fue condenado a 19 años de prisión por cometer crímenes de guerra. ${ }^{78}$

A raíz de lo anterior se proclamó lo siguiente: "all international businessmen are put on notice that business with regimes like Charles Taylor's can lead to involvement with and liability for international crimes". ${ }^{79}$ Resulta, pues, palpable la relación que en este caso se articula en torno a ciertas actividades empresariales y la comisión de ilícitos de envergadura. Todo ello conduce a la aplicación de la regulación internacional en materia de derechos humanos a un ámbito extremadamente complejo en el que parecen desdibujarse los límites. ${ }^{80}$

El impacto de la citada resolución judicial debe conjugarse con los interesantísimos Principios de Maastricht sobre las obligaciones extraterritoriales de los Estados en el área de los derechos económicos, sociales y culturales, los cuales — dotados de un alto valor doctrinal - abogan por el reconocimiento de la responsabilidad de organismos internacionales como el Fondo Monetario Internacional, así como de las empresas multinacionales. ${ }^{81}$

Se advierte, pues, la existencia de iniciativas/medidas que, desde nuestro punto de vista, agitan la cuestión objeto del presente análisis. Es más, a raíz de lo comentado en el párrafo anterior, muchos sostienen que la sub-

78 Disponible en: http://elpais.com/elpais/2017/04/24/africa_no_es_un_pais/149304880 7_263608.html.

79 Disponible en: http://www.ijrcenter.org/2017/05/03/dutch-businessman-convicted-of-warcrimes-committed-in-liberia-and-guinea.

80 Así queda determinado por SLIM cuando afirma la siguiente cuestión: "the boundary between business and humanitarian concerns has become much more porous". Cfr. Slim, H., "Business actors in armed conflict: towards a new humanitarian agenda", International Review of the Red Cross, vol. 94, núm. 887, 2002, p. 910.

81 Disponible en: https: / / www.fidh.org/IMG/pdf/maastricht-eto-principles-es_web.pdf. 
Esta revista forma parte del acervo de la Biblioteca Jurídica Virtual del Instituto de Investigaciones Jurídicas de la UNAM

jetividad de las personas jurídicas no presenta excesivos problemas desde el punto de vista técnico-jurídico; de hecho, consideran que el principal escollo reside en advertir una auténtica voluntad política que abogue por dicho reconocimiento. ${ }^{82}$ Siendo así las cosas, se entiende la razón por la que algunos autores hablan de lo positivo de defender la personalidad jurídica internacional de aquéllas en la medida en que redundaría en una situación favorable, en términos de efectividad, de la regulación internacional, tal y como se desprende de la siguiente afirmación: "a process that excluded powerful international actors will become less legitimate in the eyes of the excluded actors and will breed disrespect for the international system as a whole". ${ }^{83}$

Asimismo, en línea con lo anterior, debe ponerse de relieve la idea que figura a continuación: "an approach to international legal personality that is incapable of making all of the important actors in the international system subject to the «international rule of law» creates intolerable gaps in the structure of the international normative order and «imposes unnecessary risks on the inherently frail international legal system»" ${ }^{84}$

Consecuentemente, si finalmente llega a producirse el reconocimiento de la personalidad jurídica internacional de las empresas, cabría inferir la desaparición de la figura de la inmunidad que éstas, lamentablemente, parecen seguir gozando al día de hoy. ${ }^{85}$

De esta manera, debemos analizar, como haremos en el punto siguiente, el impacto que están generando las estrategias recientemente auspiciadas y diseñadas por la comunidad internacional, puesto que nos ayudarán a extraer conclusiones que, sin duda, aportarán "luz" en este, todavía, "tenebroso" y confuso debate.

82 Ponencia de Felipe Gómez Isa en el seminario titulado del siguiente modo: "Los derechos humanos en el ámbito empresarial: qué, cómo y por qué es posible regular en la materia”. Éste tuvo lugar en la Universidad Carlos III de Madrid, los días 18 y 19 de mayo de 2017.

83 Cfr. Charney, J. I., “Transnational Corporations and developing Public International Law”, Duke Law Journal, vol. 748, 1983, p. 787.

${ }^{84}$ Cfr. Nowrot, K., op. cit., pp. 10 y 11.

85 Ibidem, p. 767. 
Esta revista forma parte del acervo de la Biblioteca Jurídica Virtual del Instituto de Investigaciones Jurídicas de la UNAM

\section{V. ¿ES LA ACTUACIÓN DE LA ORGANIZACIÓN DE LAS NACIONES UNIDAS UNA TÁCTICA PARA PROMOVER LA SUBJETIVIDAD INTERNACIONAL DE LAS PERSONAS JURÍDICAS?}

Como ya fue apuntado, no cabe duda de que la relevancia de la regulación internacional en materia de derechos humanos ha provocado, hasta el día de hoy, un cambio sustancial, así como la vigorosa y pujante entrada en escena de numerosos actores. Siendo así las cosas, se advierte la importancia que tiene el cada vez más enconado debate surgido en torno a las razones que esgrimen unos y otros en lo que respecta a si debería llegar a admitirse o no cierto grado de subjetividad internacional en favor de las personas jurídicas.

Esta enérgica discusión debe examinarse a la luz de la postura adoptada por relevantes sujetos internacionales como lo es, sin duda, la Organización de las Naciones Unidas, lo que implica necesariamente referirnos al ya citado informe del ex representante especial del secretario general, John Ruggie, conforme al cual se presentaron los principios que deben regir en toda actuación empresarial con el propósito de proteger y respetar adecuadamente los derechos humanos, así como proporcionar el remedio oportuno, en caso de que se produzca un atentado contra los mismos. ${ }^{86}$

En este sentido, debe apuntarse que el comentado informe recalca, como no podía ser de otro modo, no sólo que las empresas juegan un papel fundamental en la sociedad, sino que además deben cumplir con "todas las leyes aplicables y respetar los derechos humanos". ${ }^{87} \mathrm{Al}$ hilo de lo anterior, es de sumo interés traer a colación el onceavo principio en virtud del cual se determina que para la consecución del comentado objetivo es necesario que éstas se abstengan de "infringir los derechos humanos de terceros y hacer frente a las consecuencias negativas sobre los derechos humanos en las que tengan alguna participación”.

Asimismo, resulta conveniente mencionar el duodécimo principio en la medida en que proclama que debido a la influencia que una empresa es capaz de ejercer por medio de sus actuaciones en el ámbito de los derechos humanos, éstas deben respetar los que se encuentran "internacionalmente

86 Disponible en: http://www.global-business-initiative.org/wp-content/uploads/2012/07/GP s-Spanish.pdf.

87 Ibidem. 
Esta revista forma parte del acervo de la Biblioteca Jurídica Virtual del Instituto de Investigaciones Jurídicas de la UNAM

reconocidos — que abarcan, como mínimo, los derechos enunciados en la Carta Internacional de Derechos Humanos y los principios relativos a los derechos fundamentales establecidos en la Declaración de la Organización Internacional del Trabajo relativa a los principios y derechos fundamentales en el trabajo_-". En definitiva, "las empresas deben cumplir todas las leyes aplicables y respetar los derechos humanos internacionalmente reconocidos, donde quiera que operen”. Para ello, es esencial que, tal y como concreta el instrumento en cuestión, las personas jurídicas asuman un compromiso de respeto para con aquéllos, se actúe con la diligencia debida, se reparen los daños causados, etcétera.

Del citado informe se deducen, grosso modo, tres ideas esenciales. La primera cuestión sobre la que se presta especial atención es la que se refiere al deber estatal de proteger en el momento en el que se producen violaciones contra los derechos humanos acaecidos en su territorio y/o en su jurisdicción, incluyendo ilícitos cometidos por las empresas. La segunda idea se encuentra relacionada con el importante concepto de responsabilidad corporativa. Y la tercera hace hincapié en la necesidad de facilitar un acceso efectivo a los recursos — tanto judiciales como extrajudiciales - con la intención de promover una reparación adecuada frente a los daños ocasionados. ${ }^{88}$ Se trata, por tanto, de un documento que trata de imponer "orden” en las actuaciones empresariales para que las mismas tengan lugar de acuerdo con lo estipulado por la normativa relativa a los derechos humanos. Consecuentemente, se advierten avances innegables, máxime si se toma en consideración que, poco años atrás, se afirmaba lo siguiente:

though corporations are capable of interfering with the enjoyment of a broad range of human rights, international law has failed both to articulate the human rights obligations of corporations and to provide mechanisms for regulating corporate conduct in the field of human rights... Over the last fifty years, though, the gradual establishment of an elaborate regime of international human rights law and international criminal law has begun to redefine the individual's role under international law. It is now generally accepted that individuals have rights under international hu-

88 Con respecto a esta última cuestión, debemos apuntar que los mecanismos de reparación existentes son incompletos y, por tanto, deben ser objeto de una sustancial mejora, tal y como se desprende del informe emitido en el año 2008 conocido como Marco de las Naciones Unidas para Proteger, Respetar y Remediar, disponible en: https://business-humanrights.org/ sites/default/files/reports-and-materials/Ruggie-report-7-Apr-2008.pdf. 
Esta revista forma parte del acervo de la Biblioteca Jurídica Virtual del Instituto de Investigaciones Jurídicas de la UNAM

man rights law and obligations under international criminal law. This redefinition, however, has occurred only partially with respect to legal persons such as corporations: international law views corporations as possessing certain human rights, but it generally does not recognize corporations as bearers of legal obligations under international criminal law". 89

Sea como fuere, conviene apuntar que, con carácter previo al citado informe, se articularon, en su momento, otra clase de iniciativas caracterizadas no sólo por plasmar la preocupación existente en este campo, sino también por motivar el establecimiento de una relación entre las personas jurídicas y la regulación supranacional en materia relativa a los derechos humanos. Es más, hace años, se tuvo la oportunidad de poner de relieve que los ingresos procedentes, fundamentalmente, de grandes multinacionales eran superiores al PIB de algunos Estados; asimismo, se hizo hincapié en que la actuación de aquéllas afectaba en gran medida a los derechos más básicos de los individuos, etcétera. Lo anterior explica la aparición en su día de la Comisión de Sociedades Transnacionales o del Centro de Sociedades Transnacionales, encargados de elaborar, entre otras cosas, eficaces códigos de conducta.

Posteriormente, la llegada del nuevo siglo trajo consigo estrategias conforme a las cuales se pretendía promover un "comportamiento responsable en el ámbito de los derechos humanos, el trabajo, el medio ambiente y la lucha contra la corrupción"90 que tuviera repercusión en la esfera de actuación empresarial mediante un "enfoque de precaución en lo relativo a los desafíos medioambientales, la promoción de una mayor responsabilidad medioambiental; y el desarrollo y la difusión de tecnologías favorables al medio ambiente". ${ }^{91}$

Al hilo de lo anterior, reviste especial interés el documento adoptado, en 2003, por la Subcomisión de Promoción y Protección de los Derechos Humanos de las Naciones Unidas, titulado "Normas de la ONU sobre la responsabilidad de las empresas transnacionales y otras empresas en relación a los derechos humanos". ${ }^{92}$ A través de éste, se detalló un listado de cuestiones

89 Véase Developments in the Law-Corporate Liability for Violations of International Human Rights Law, Harvard Law Review, núm. 114, May 2001, pp. 2030 y 2031.

90 Véase el documento titulado del siguiente modo: "Análisis de los resultados medioambientales de la OCDE: España 2015”, p. 222.

91 Idem.

92 Disponible en: http://observatoriorsc.org/wp-content/uploads/2013/11/Normas_DDHH_ ONU.pdf. 
Esta revista forma parte del acervo de la Biblioteca Jurídica Virtual del Instituto de Investigaciones Jurídicas de la UNAM

a las que las empresas debían prestar especial atención (por ejemplo, la prohibición de trabajo infantil), advirtiendo la responsabilidad de los Estados en caso de no poder cumplir con las premisas esenciales de aquél.

Además, con el propósito de garantizar su efectividad se concretaron procedimientos que pretendían verificar de forma independiente el grado de conculcación del mismo, así como facilitar eficaces procesos de denuncia. Siendo así las cosas, un amplio sector empresarial mostró su desdén para con aquél, puesto que lo consideraron una fuerte amenaza que podría perjudicarles seriamente. Ello, finalmente, se tradujo en la falta de imperatividad y, por tanto, de inoperatividad de las Normas de 2003.

Así pues, la cuestión relativa a las empresas y los derechos humanos seguía siendo, por aquel entonces, un capítulo sin cerrar, lo que generó una fuerte expectación en los años siguientes en relación con otras estrategias que en aquél momento empezaban a gestarse. Así, más adelante, en el año 2008, se sitúa el Marco de Naciones Unidas "Proteger, Respetar, Remediar", conforme al cual se hizo referencia a los principios fundamentales sobre los que toda acción empresarial debería articularse. ${ }^{93} \mathrm{Y}$, por fin, tres años después, se aprobaron los ya citados "Principios Rectores sobre las empresas y los derechos humanos: puesta en práctica del marco de las Naciones Unidas para proteger, respetar y remediar”.

Una vez analizado brevemente el recorrido histórico en torno a las medidas adoptadas en este peculiar y complejo ámbito, conviene volver al informe del año 2011, el cual fue, para muchos, un tanto decepcionante, pues - tal y como proclama su anexo- "en ningún caso debe interpretarse que estos principios rectores establezcan nuevas obligaciones de derecho internacional ni que restrinjan o reduzcan las obligaciones legales que un estado haya asumido, o a las que esté sujeto de conformidad con las normas de derecho internacional en materia de derechos humano". Siendo así las cosas, no nos sorprenden las afirmaciones siguientes

el contenido del informe es tan solo y únicamente, una interpretación de las obligaciones ya nacidas de las que se asumieron en su día por los estados en virtud de otros convenios internacionales de derechos humanos; esto es, una recomendación de su aplicación, lo que en definitiva puede llevar a la conclusión por la cual en la

93 Disponible en: http: / / observatoriorsc.org/wp-content/uploads/2013/11/Proteger_respetar_ remediar_abri12008.pdf. 
Esta revista forma parte del acervo de la Biblioteca Jurídica Virtual del Instituto de Investigaciones Jurídicas de la UNAM

práctica jurídica dichos principios carecen de validez. Así pues, pudiera pensarse que estas obligaciones, no son sino pura tautología. ${ }^{94}$

Parece, pues, que el instrumento objeto de análisis no añade nada nuevo de interés. Es más, si se examina con detalle el documento en cuestión, no sólo resulta decepcionante su anexo, sino que el cuerpo principal del texto también genera esa misma impresión. En el momento en el que se determina que el Estado debe asegurar que las empresas cumplan con la regulación en materia de derechos humanos, uno es capaz de percibir la falta de trascendencia de dicha aseveración. Obviamente, en un Estado de derecho se debe conferir la pertinente protección y asegurar el cumplimiento de la normativa existente en materia de derechos humanos, por lo que el principio rector cuarto no es más que una obviedad que no contiene valor añadido alguno. Lo mismo sucede con el principio rector tercero cuando menciona que la regulación mercantil doméstica debe promover el respeto de la normativa anteriormente citada.

De nuevo, si estamos ante un país que ha suscrito debidamente los tratados de turno, difícilmente podrá aplicarse una regulación nacional que colisione con aquélla. No hay duda de que son los Estados los que, al comprometerse con las normas nacionales y supranacionales relativas a los derechos humanos, deben exigir un fiel cumplimiento de las mismas, y ello, por supuesto, incluye a todo operador que actúe en su territorio y/o jurisdicción. Así pues, como ya decíamos, es difícil apreciar un contundente impacto en lo que al contenido del citado informe se refiere.

No obstante lo anterior, conviene apuntar que el mencionado informe, al tratar la idea relativa a la reparación de los daños causados, determina que deben ser las empresas las que se involucren y, por tanto, las que — “empleándose a fondo" _ confieran remedio a "esa situación, por sí sola o en

94 Cfr. Esteve Moltó, J. E., "Los Principios Rectores sobre las empresas transnacionales y los derechos humanos en el marco de las Naciones Unidas para «proteger, respetar y remediar»: ¿hacia la responsabilidad de las corporaciones o la complacencia institucional?”, Anuario Español de Derecho Internacional, vol. 27, 2011, p. 329. No obstante, conviene tener presente que, en opinión de Cantú Rivera, existían una serie dificultades — en el momento de la elaboración de los referidos principios - las cuales descansaban, básicamente, "en la falta de un punto de convergencia a partir del cual pudiera construirse un progreso significativo". Cfr. Cantú Rivera, H., "Derechos humanos y empresas: hacia una conducta empresarial responsable”, Revista del Centro Nacional de Derechos Humanos, núm. 11, 2016, p. 43. 
Esta revista forma parte del acervo de la Biblioteca Jurídica Virtual del Instituto de Investigaciones Jurídicas de la UNAM

cooperación con otros actores". ${ }^{95}$ En este ámbito, parece que se invierten los roles entre las personas jurídicas y los Estados, siendo la actuación de las primeras la prioritaria. Es más, si la "consecuencia negativa” generada no ha sido motivada por la empresa, pero existe una "relación directa con operaciones, productos o servicios prestados por una relación comercial suya", podrá, si así lo desea, adoptar un "papel” en el proceso de reparación. En cualquier caso, aunque se transfiere a las empresas el protagonismo en este ámbito, debe admitirse que la terminología empleada no es precisamente contundente; de hecho, queda impregnada por altas dosis de voluntariedad, lo cual dulcifica y suaviza la trascendencia de aquél. ${ }^{96}$

Redundando en la premisa anterior, cabe traer a colación la opinión de Esteve Moltó en la medida en que afirma que el instrumento objeto de análisis se decanta con un extremo cuidado por un determinado vocabulario conforme al cual se evitan términos como "obligaciones"; inclinándose por un "leguaje soft de forma deliberada con referencias como «se espera», «deberían informar», «diligencia debida», «debe emplearse a fondo», etc." ${ }^{97}$ Es más, en cuanto a las empresas que actúan más allá de su propio territorio, el citado autor indica que

el informe se conforma con enunciar genéricamente que estas empresas respeten los derechos humanos, una vez que el Estado les diga y «espere» que este debe ser su comportamiento «previsible» más allá de sus fronteras, ignorando con ello planteamientos más combativos. Y todo ello, con el loable fin «de preservar la reputación del estado». Así pues, Ruggie, como hiciera en el informe de 2009, no soluciona el problema de la extraterritorialidad y se limita a describir los distintos enfoques que de forma unilateral están adoptando cada uno de los Estados. ${ }^{98}$

95 Nos estamos refiriendo al principio rector 22.

96 Una idea parecida se obtiene al advertir que se requiere al Estado que exija diligencia debida a las empresas con el propósito de procurar una protección adecuada contra agresiones de los derechos humanos. Parece claro, pues, que la ardua y compleja tarea, en este sentido, la asume el Estado.

97 Cfr. Esteve Moltó, J. E., op. cit., p. 330. Asimismo, el autor añade lo siguiente: "la obligación de protección en caso de conflicto puede parecer un tanto débil, si se atiende al enunciado del principio que indica que los Estados «deben tratar de asegurar» que las empresas que desarrollan su actividad en estas situaciones no se vean envueltas en violaciones de derechos humanos”. Cfr. Esteve Moltó, J. E., op. cit., p. 333.

98 Ibidem, p. 331. 
Esta revista forma parte del acervo de la Biblioteca Jurídica Virtual del Instituto de Investigaciones Jurídicas de la UNAM

Por tanto, el panorama que dibujan los Principios de Ruggie no es nada alentador, máxime si consideramos la falta de imperatividad de los mismos. En definitiva, no se trata de un instrumento obligatorio, y es precisamente por esa misma razón por la que muchas personas jurídicas se han mostrado favorables y "abiertas" a acoger su contenido, tal y como declara Amnistía Internacional. ${ }^{99} \mathrm{~A}$ nuestro modo de ver, este pequeño pero vital matiz lo cambia todo. De manera similar concluye Human Rights Watch cuando afirma que el informe del año 2011 se limita a perpetuar el status quo de las empresas. ${ }^{100}$

No obstante, algunos autores esperanzados no desdeñan la importancia de los citados principios rectores en la medida en que sostienen que tanto éstos como los trabajos previos que desembocaron en su realización han implicado un enfrentamiento con respecto a la doctrina clásica relativa a la subjetividad internacional. Así lo entienden algunos cuando afirman lo siguiente: "Ruggie's reports indicate that in the course of the past few decades, the legal status of corporations in international law has shifted to some extent from the classical position, with corporations now considered bearers of duties under international criminal law". ${ }^{101}$

Así pues, cierto sector doctrinal aprecia vientos de cambio propicios a facilitar un eficaz marco de protección en el campo de una regulación relativa a los derechos humanos ligada a la actuación empresarial. Claramente, se está generando una corriente de opinión conforme a la cual parece plausible que se produzca una modificación del paradigma tradicionalmente imperante, pese a que en estos momentos no se están produciendo cambios legislativos de importante calado y que, además, los Estados siguen siendo los únicos sujetos que juegan un papel esencial en la materia en cuestión. Por lo tanto, pese a los puntos flacos que sin duda alguna rodean a los Principios Ruggie, ${ }^{102}$ existe cierto empecinamiento en argumentar que los mismos se erigen como una especie de trampolín capaz de allanar el camino hacia la creación, por ejemplo, de derecho consuetudinario en materia de responsabilidad empresarial, en relación con conductas lesivas para con los

\footnotetext{
99 Disponible en: https: / / www.ft.com/content/a3101700-2439-11e0-a89a-00144feab49a.

100 Disponible en: https: / / www.hrw.org/news/2011/06/16/un-human-rights-council-weak-stan ce-business-standards.

101 Cfr. Duruigbo, E., op. cit., p. 224.

102 El principal argumento negativo que se esgrime es que se trata de un instrumento del soft law, advirtiendo su marcado e ineficiente carácter "autorregulatorio".
} 
Esta revista forma parte del acervo de la Biblioteca Jurídica Virtual del Instituto de Investigaciones Jurídicas de la UNAM

derechos humanos. ${ }^{103} \mathrm{Al}$ hilo de lo anterior, cabe traer a colación la postura de Márquez Carrasco, puesto que muy hábilmente ha comentado que este tipo de herramientas pueden llegar a considerarse actos unilaterales cristalizadores de compromisos con capacidad para crear una opinio iuris individual. ${ }^{104}$ Sea como fuere, de lo que no hay duda es que el impacto de los principios rectores dependerá de la "influencia que tengan sobre otras organizaciones e instituciones, y sobre la política pública, así como por las posibilidades creadas cuando sean aplicados por Gobiernos y empresas". ${ }^{105}$

Como colofón a lo anterior, cabe mencionar una cuestión que, de alguna manera, apoya la tesis anterior. Nos estamos refiriendo, evidentemente, al grupo de trabajo intergubernamental creado con el propósito de elaborar un instrumento internacional jurídicamente vinculante en el ámbito relativo a los derechos humanos en relación con las actividades realizadas por compañías transnacionales y otras empresas. A raíz de la citada iniciativa, se emitió un informe, en febrero de 2016, ${ }^{106}$ acerca de la necesidad de vincular a las personas jurídicas con la citada regulación, puesto que éstas - tal y como se indicó en la resolución 26/9 de 2014 — "tienen la capacidad de fomentar el bienestar económico, el desarrollo, el progreso tecnológico y la riqueza, así como de provocar repercusiones negativas para los derechos humanos". ${ }^{107}$ Abundando en el contenido de aquél, debe traerse a colación de forma literal la siguiente afirmación: "los Principios Rectores eran com-

103 Véase Cefo, E., "Corporate Human Rights Violation in the Occupied Palestinian Territories”, Georgetown Journal of International Law, vol. 47, 2016, p. 818.

104 Ponencia de Carmen Márquez Carrasco en el seminario titulado del siguiente modo: "Los derechos humanos en el ámbito empresarial: qué, cómo y por qué es posible regular en la materia”. Éste tuvo lugar en la Universidad Carlos III de Madrid, los días 18 y 19 de mayo de 2017.

105 Cfr. Márquez Carrasco, C., "El plan nacional de España sobre empresas y derechos humanos y la implementación de los pilares proteger, respetar y remediar: oportunidades y desafíos", España y la implementación de los principios Rectores de las Naciones Unidas sobre empresas y derechos humanos: oportunidades y desafios, Barcelona, Huygens, 2014, p. 42.

106 Se trata del informe del primer periodo de sesiones del grupo de trabajo intergubernamental de composición abierta sobre las empresas transnacionales y otras empresas con respecto a los derechos humanos, con el mandato de elaborar un instrumento jurídicamente vinculante.

107 Nos referimos al documento elaborado por el Consejo de Derechos Humanos relativo a la "Promoción y protección de todos los derechos humanos, civiles, políticos, económicos, sociales y culturales, incluido el derecho al desarrollo", disponible en: http: / / ap.ohchr.org/ docu ments/S/HRC/d_res_dec/A_HRC_26_L22.pdf. 
Esta revista forma parte del acervo de la Biblioteca Jurídica Virtual del Instituto de Investigaciones Jurídicas de la UNAM

plementarios, no contradictorios, con un instrumento jurídicamente vinculante, que la adopción de un instrumento de esa índole podría contribuir a proteger a los más vulnerables". ${ }^{108}$

Así pues, parece que se producen avances encaminados a abordar de lleno la cuestión objeto de análisis, y lo más significativo es que, con esta nueva estrategia, parece que pretende hacerse de forma eficaz al abogar por la creación de una herramienta jurídica imperativa. Si la estrategia en ciernes termina por cuajar, no hay duda de que la normativa en materia de derechos humanos quedará debidamente apuntalada y fortalecida. No sólo eso, se generarían, además, cambios de calado en la esfera de la normativa internacional, ya que ello afectaría a la percepción tradicional que durante años se ha tenido sobre el ámbito de la subjetividad internacional en la medida que se reconocería la misma en el campo de las empresas transnacionales y otras empresas, ${ }^{109}$ frenando con ello el, hasta ahora, aplastante, imparable e inmune poder corporativo.

\section{CONCLUSIONES}

A raíz de lo comentado en los apartados previos, no hay duda del marcado carácter estatal que presenta la sociedad internacional. Siendo así las cosas, no debe desdeñarse el hecho de que ésta ha ido evolucionando de forma significativa en los últimos años. Así se aprecia, por ejemplo, el destacado papel que otrora actores y actualmente sujetos de derecho internacional están desempeñando en el seno de la comunidad internacional. Además, en este contexto, debe traerse a colación el indubitado proceso de humanización al que se ha visto sometido la normativa supranacional, provocando alteraciones significativas en su "fisonomía". Siendo conscientes de la trascendencia de ambos factores, no nos resulta extraño el debate que se plantea acerca de si las personas físicas y jurídicas, tradicionalmente no catalogadas como sujetos desde el punto de vista de la regulación supranacional, puedan ser

108 Véase supra nota al pie 106.

109 Tal y como determina la resolución 26/9, "otras empresas" implica referirse a "todas las empresas cuyas actividades operacionales tienen carácter transnacional y no se aplica a las empresas registradas a nivel local con arreglo a la legislación nacional pertinente”. 
Esta revista forma parte del acervo de la Biblioteca Jurídica Virtual del Instituto de Investigaciones Jurídicas de la UNAM

finalmente consideradas como tales. A este respecto, debemos subrayar que existe cierto consenso en torno a la personalidad jurídica internacional del individuo, si bien es cierto que éste no constituye al día de hoy un capítulo totalmente superado.

Y, como no podía ser de otro modo, la anterior discusión se ha trasladado al marco de las personas jurídicas. No obstante, debido a las diferencias notables y más que evidentes que existen entre éstas y las personas físicas, no ha podido establecerse un paralelismo sin más que ayude a suavizar el debate, el cual constituye - para algunos - una aberración en la medida en que no debería admitirse - bajo ningún concepto - la subjetividad de las corporaciones. Como era de esperar, frente a la postura previa, encontramos otros que defienden tal posibilidad, argumentando - entre otros motivos - que los obstáculos que se atisban son puramente políticos y no de carácter técnico-jurídico.

En cualquier caso, pese a la falta de consenso existente en este ámbito, parece haberse avivado el debate con la implementación, en los últimos años, de ciertas estrategias diseñadas por parte de la Organización de las Naciones Unidas. En este contexto, debe examinarse con cautela el informe auspiciado por John Ruggie, ex representante especial del secretario general para la cuestión de los derechos humanos y las empresas transnacionales y otras empresas, en 2011, puesto que trató de generar las pertinentes sinergias entre la actuación de las personas jurídicas y la regulación relativa a los derechos humanos.

Como vimos, el documento en muchos extremos no añade nada nuevo y, además, su falta de imperatividad minimiza, en gran medida, el impacto que - en un momento dado - podría haber llegado a tener. No obstante, no hay que olvidar los efectos que ha generado, ya que - como hemos advertido - ha contribuido a agitar un debate que, si bien se encontraba abierto hace décadas, parece estar llegando a su punto álgido. De hecho, un buen ejemplo de la afirmación anterior es la misión asumida recientemente por un grupo de trabajo intergubernamental consistente en elaborar un instrumento internacional jurídico de carácter vinculante en el ámbito relativo a los derechos humanos, en relación con las actividades realizadas por compañías transnacionales y otras empresas. Si esta iniciativa culmina con la adopción de la citada herramienta, cabría hablar de la cristalización de una concepción amplia de la civitas maxima, conforme a la cual la doctrina clásica relativa a la subjetividad internacional se habría visto ampliamente superada 
Esta revista forma parte del acervo de la Biblioteca Jurídica Virtual del Instituto de Investigaciones Jurídicas de la UNAM

al reconocer su titularidad a favor o en detrimento — según se mire — de las personas jurídicas. Sin duda, ello agitaría los pilares esenciales del orden legal internacional, pero también redundaría — y de ahí lo positivo de la maniobra en cuestión - en un mayor grado de credibilidad del mismo.

Consecuentemente, los Principios Ruggie pueden considerarse como una plataforma de partida que debe valorarse en su justa medida. ${ }^{110}$ En definitiva, pese a la falta de contundencia de los comentados principios rectores, ${ }^{111}$ abogar por establecer una relación entre las empresas y las normas de derechos humanos no debe contemplarse como algo negativo; máxime si éstos originan una enérgica controversia y alientan, a su vez, de forma directa o indirecta, estrategias con loables objetivos, como el de elaborar un tratado internacional vinculante para las personas jurídicas.

De alguna manera, el informe de 2011 puede apreciarse como un acicate a favor de la lucha contra las desmesuradas y, en ocasiones, descontroladas actuaciones empresariales. Así, conviene tener presente las siguientes palabras vertidas en torno a los citados principios rectores: "[they] will not bring business and human right challenges to an end. But it will mark the end of the beginning: by establishing a common global platform for action, on which cumulative progress can be built step by step, without foreclosing any other promising longer-term developments". ${ }^{112}$ En definitiva, parece que existe cierta determinación a la hora de imponer límites a los excesos que la lex mercatoria ha sabido potenciar en muchos momentos. Falta esperar y comprobar si finalmente las acertadas medidas en ciernes culminan conforme a lo esperado, impulsando una auténtica y eficaz protección de las normas relativas a los derechos humanos en un sector tan controvertido como lo es, sin duda, el empresarial.

110 Véase Bilchitz, D., “El Marco Ruggie: ¿Una propuesta adecuada para las obligaciones de derechos humanos?”, vol. 7, núm. 12, 2010, p. 229.

111 Ello sólo puede explicar la calurosa acogida que los Principios Ruggie suscitaron en el sector empresarial mundial.

112 Se trata de las declaraciones proferidas por el antiguo representante especial del secretario general para la cuestión de los derechos humanos y las empresas transnacionales y otras empresas. En este sentido, véase el siguiente documento: "Guiding Principles on Business and Human Rights: Implementing the United Nations «Protect, Respect and Remedy» framework”, A/HRC/17/31, 2011, párrafo 13. 
Esta revista forma parte del acervo de la Biblioteca Jurídica Virtual del Instituto de Investigaciones Jurídicas de la UNAM

\section{BIBLIOGRAFÍA}

BARBERIS, J., "La personalidad jurídica internacional”, Los sujetos de derecho internacional, Madrid, Tecnos, 1984

BilchitZ, D., "El Marco Ruggie: ¿Una propuesta adecuada para las obligaciones de derechos humanos?", vol. 7, núm. 12, 2010.

Bodin, J., "Libro primero; Capítulos VII-X", Los seis libros de la República, Madrid, Aguilar, 1973.

CANÇADO TRINDADE, A. A., "La persona humana como sujeto del derecho internacional: avances de su capacidad jurídica internacional en la primera década del siglo XXI", Revista IIDH, vol. 46, 2007.

CANTÚ RIVERA, H., "Derechos humanos y empresas: hacia una conducta empresarial responsable", Revista del Centro Nacional de Derechos Humanos, núm. 11, 2016.

CARPizO, J., "La Soberanía del pueblo en el derecho interno y en el internacional", REP, núm. 28, 1982.

CASSESE, A., Los derechos humanos en el mundo contemporáneo, Barcelona, Ariel, 1993.

CAssese, A., International Law, 2a. ed., Oxford University Press, 2005.

CEFO, E., "Corporate Human Rights Violation in the Occupied Palestinian Territories", Georgetown Journal of International Law, vol. 47, 2016.

Chinchón Álvarez, J. " "Responsabilidad internacional del individuo y responsabilidad internacional del Estado: encuentros y desencuentros en torno a la figura de los crímenes de derecho internacional", Protección internacional de derechos humanos y Estado de derecho, Bogotá, Grupo Editorial Ibáñez, 2009.

Duruigbo, E., "Corporate Accountability and Liability for International Human Rights Abuses: Recent Changes and Recurring Challenges", Northwestern Journal of International Human Rights, vol. 6, núm. 2, 2008.

Esteve Moltó, J. E., "Los Principios Rectores sobre las empresas transnacionales y los derechos humanos en el marco de las Naciones Unidas para «proteger, respetar y remediar»: ¿hacia la responsabilidad de las corporaciones o la complacencia institucional?", Anuario Español de Derecho Internacional, vol. 27, 2011. 
Esta revista forma parte del acervo de la Biblioteca Jurídica Virtual del Instituto de Investigaciones Jurídicas de la UNAM

García Mosquera, M., "La personalidad jurídica de empresas transnacionales como requisito de la responsabilidad penal del art. 31 bis CP”, Estudios Penales y Criminológicos, vol. 33, 2013.

Nowrot, K., "New Approaches to the International Legal Personality of Multinational Corporations: Towards a Rebuttable Presumption of Normative Responsibility”; artículo entregado en "Geneva Reasearch Forum on International Law” y organizado por la European Society of International Law, 2005.

PASTOR PASTOR Ridruejo, J. A., "El individuo en el derecho internacional”, Curso de derecho internacional público y organizaciones internacionales, Madrid, Tecnos, 2016.

Rosas Castañeda, J. A., "Hacia el jus standi del individuo en el procedimiento ante la Corte Interamericana de Derechos Humanos", Revista CEJIL, núm. 3, 2007.

SepúlvedA, C., "Soberanía y derecho internacional”, Derecho internacional público, 2a. ed., México, Porrúa, 1964.

SLIM, H., "Business actors in armed conflict: towards a new humanitarian agenda”, International Review of the Red Cross, vol. 94, núm. 887, 2002.

VACAS FERNÁNDEZ, F., "Fundamento jurídico internacional; la subjetividad internacional de Naciones Unidas y su sometimiento al derecho internacional”, La responsabilidad internacional de Naciones Unidas, Madrid, Dykinson, 2002. 